\title{
A comparative study of the effectiveness of vibration and acoustic emission in diagnosing a defective bearing in a planetary gearbox
}

\author{
Faris Elasha ${ }^{1^{*}}$, Matthew Greaves ${ }^{2}$, David Mba $^{3}$, Duan Fang ${ }^{3}$ \\ ${ }^{1}$ Faculty of Engineering, Environment and computing, Coventry University (UK) \\ ${ }^{2}$ School of Engineering, Cranfield University (UK) \\ ${ }^{3}$ School of Engineering, London South Bank University (UK)
}

\begin{abstract}
Whilst vibration analysis of planetary gearbox faults is relatively well established, the application of Acoustic Emission (AE) to this field is still in its infancy. For planetary-type gearboxes it is more challenging to diagnose bearing faults due to the dynamically changing transmission paths which contribute to masking the vibration signature of interest.
\end{abstract}

The present study is aimed to reduce the effect of background noise whilst extracting the fault feature from $A E$ and vibration signatures. This has been achived through developing of internal AE sensor for helicopter transmission system. In addition, series of signal processing procedure has been developed to improved detection of incipient damage. Three signal processing techniques including an adaptive filter, spectral kurtosis and envelope analysis, were applied to $A E$ and vibration data acquired from a simplified planetary gearbox test rig with a seeded bearing defect. The results show that $A E$ identified the defect earlier than vibration analysis irrespective of the tortuous transmission path.

*Corresponding author. Tel: +44 (0) 2477659139. 


\section{Introduction}

Planetary gearboxes are important components of rotating machines due to their high transmission ratio, higher torque to weight ratio and high efficiency [1]. As such this type of gearbox is widely used in many industries such as aerospace, wind turbines, mining and heavy trucks [2-6]. Different planetary gearbox configurations and designs allow for a range of gear ratios, torque transmission and shaft rotational characteristics. The planetary gearbox generally operates under severe conditions, thus the gearbox components are subject to different kinds of fault conditions such as gear pitting, cracks, etc. [7-10]. Recent investigations on wind turbine applications of planetary gearboxes have shown that failures initiate at a number of specific bearing locations, which then progress into the gear teeth. In addition bearing debris and the resultant excess clearances cause gear surface wear and misalignment [10]. The accident to G-REDL [11], resulting in the loss of 16 lives, was caused by degradation of a planet gear bearing, resulting in the failure of the planet gear and, as a result, the loss of the aircraft.

Several authors have proposed numerous diagnostic approaches for planetary gearboxes, with vibration analysis the most commonly employed monitoring technology $[1 ; 7 ; 9 ; 12-14]$. However, fault detection of bearings within the planetary gearbox is one of the most challenging diagnostic scenarios, as the resulting vibration signatures are influenced by the variable transmission paths from the bearing to the receiving externally mounted sensor. This leads to strong background noise which can mask the vibration signature of interest. This task is compounded by the fact that the gear mesh frequencies typically dominate the resultant vibration signal $[7 ; 13 ; 15]$.

Early attempts utilized time domain averaging to separate the gear components from the measured vibration signal in order to reduce the signal-to-noise ratio (SNR). This involves combining a delayed version of the measured vibration signal with the original signal thereby reinforcing certain frequency components, whilst eliminating others. However, the signal to noise ratio (SNR) enhancement with this technique is not always sufficient to aid detection of bearing faults and hence this technique has not proved successful in identifying bearing defects within planetary gearboxes [7]. Time Synchronous Averaging (TSA) has also been applied to separate the bearing vibration components from the measured gearbox signature 
[13; 16-19]. This minimises the influence of speed variation by re-sampling the signal in the angular domain [13]. The process of re-sampling the signal requires a tachometer or phase marker and is not commonly applied for the sole purpose of separating the bearing vibration signature [18].

More recently, signal separation techniques have been applied in the diagnosis of bearing faults within gearboxes. The separation is based on decomposing the signal into deterministic and random components. The deterministic part represents the gear component and the random part represents the bearing component of the measured signal. The bearing contribution to the signal is expected to be random due to slip effects $[8 ; 18 ; 20$; 21]. A number of methods for signal separation are available, each having relative advantages and disadvantages [18; 22-24]. Techniques such as Linear Prediction (LP) have been employed for separation, allowing the separation of the deterministic (or predictable) part of a signal from the random background noise using the information provided by past observations $[25 ; 26]$. The results of such techniques depend on the number of past observations considered. Smaller values of past observation produce a poor prediction, giving a result of negligible improvement in the signal-to-noise ratio, while very high values compromise computation time, over-constrain the prediction and tend to reduce even the main components of the signal (both deterministic and non-deterministic parts) [27; 28]. Interestingly LP is applied only to stationary vibration signatures.

To overcome the problem of separation of non-stationary vibrations, adaptive filters were proposed. This concept is based on the Wold Theorem, in which the signal can be decomposed into deterministic and non-deterministic parts. It has been applied to signal processing in telecommunication [28] and ECG signal processing [29]. The separation is based on the fact that the deterministic part has a longer correlation than the random part and therefore the autocorrelation is used to distinguish the deterministic part from the random part. However, a reference signal is required to perform the separation. The application of this theory in condition monitoring was established by Chaturvedi et al. [30] where the Adaptive Noise Cancellation (ANC) algorithm was applied to separate bearing vibrations corrupted by engine noise, with the bearing vibration signature used as a reference signal for the separation process. However, for practical diagnostics, the reference signal is not always readily available. As an alternative, a delayed version of the signal has 
been proposed as a reference signal and this method is known as self-adaptive noise cancellation (SANC) [21] which is based on delaying the signal until the noise correlation is diminished and only the deterministic part is correlated [20].

Many recursive algorithms have been developed specifically for adaptive filters [31;32]. Each algorithm offers its own features and therefore the algorithm to be employed should be selected carefully depending on the signal under consideration. Selection of the appropriate algorithm is determined by many factors, including: convergence, type of signal (stationary or non-stationary) and accuracy [33].

The Spectral Kurtosis technique has been introduced recently for bearing signal separation $[34 ; 35]$. The basic principle of this method is to determine the Kurtosis at different frequency bands in order to identify the energy distribution of the signal and determine where the high impact energy (transient events) are located in the frequency domain. Obviously the results obtained strongly depend on the width of the frequency bands $\Delta f$ [36]. As noted earlier, in real applications background noise often masks the signal of interest and as a result the traditionally obtained Kurtosis value, in the time domain, is unable to capture the 'peakiness' of the fault signal, usually giving low Kurtosis values. Therefore, in applications with strong background noise, the Kurtosis as a global indicator is not useful, although it gives better results when it is applied locally in different frequency bands [35]. The Spectral Kurtosis (SK) was first introduced by Dwyer [37] as a statistical tool which can locate non-Gaussian components in the frequency domain of a signal. This method is able to indicate the presence of transients in the signal and show their locations in the frequency domain. It has been demonstrated to be effective even in the presence of strong additive noise [35].

In addition to the vibration analysis, the Acoustics Emission (AE) technology has emerged as a promising diagnostic approach. $\mathrm{AE}$ was originally developed for non-destructive testing of static structures, however, in recent times its application has been extended to health monitoring of rotating machines and bearings [34; 38-40]. In machinery monitoring applications, $A E$ are defined as transient elastic waves produced by the interface of two components or more in relative motion $[41 ; 42]$. AE sources include impacting, cyclic fatigue, friction, turbulence, material loss, cavitation, leakage etc. It provides the benefit of early fault detection in comparison to vibration analysis and oil analysis due to the high sensitivity to friction offered by AE [43]. Nevertheless, successful applications of $A E$ for health monitoring of a wide range of rotating machinery have been partly limited due to the difficulty in signal processing, interpreting and manipulating the acquired data [44-46]. In addition, AE signal 
processing is challenged by the attenuation of the signal and as such the AE sensor has to be close to its source. However, it is often only practical to place the AE sensor on the nonrotating member of the machine, such as the bearing housing or gearbox casing. Therefore, the $A E$ signal originating from the defective component will suffer severe attenuation and reflections, before reaching the sensor. Challenges and opportunities of applying $A E$ to machine monitoring have been discussed by Sikorska et. al and Mba et. al. [41; 47]. To date, most applications of machine health monitoring with $A E$ have targeted single components such as a pair of meshing gears [48], a particular bearing or valve [49; 50]. This targeted approach to application of AE has on the whole demonstrated success. However the ability to monitor components that are secondary to the main component of interest such as a bearing supporting a gear, as is the case with planetary gears in an epicyclical gear box, has not been well-explored. This is the first known publication to explore the ability to identify a fault condition where the $A E$ signature of interest is severely masked by the presence of gear meshing $A E$ noise.

Whilst vibration analysis of gearbox fault diagnosis is well established, the application of $A E$ to this field is still in its early stages $[43 ; 51 ; 52]$. Moreover, there are limited publications on application of $\mathrm{AE}$ to bearing fault diagnosis within gearboxes [45]. The research programme described here aims to inform the next generation of HUMS systems by identifying and proving feasibility for new, and newly- applied, sensing technologies, with a specific focus on internal sensors. In addition, This paper discusses the analysis of the vibration and AE data collected using this technology from a lab scale and full scale helicopter test rig, and compares their effectiveness in diagnosing a bearing defect in the planetary gearbox. The data was collected for various bearing fault conditions and processed using an adaptive filter algorithm to separate the non-deterministic part of the signal and enhance the signal-tonoise ratio for both $\mathrm{AE}$ and vibration. The resultant signatures were then further processed using envelope analysis to extract the fault signature.

\section{Gear and bearing diagnosis}

The vibration signals associated with bearing defects have been extensively studied and robust detection algorithms are now available as off-the-shelf solutions. Conversely the dynamics associated with bearing diagnostics within gearboxes reduce the capability of 
traditional techniques. Therefore, it is important to understand the nature of the faulty bearing signal.

For rolling element bearings, a fault will cause shocks which in turn excite higher resonance frequencies which will be amplitude modulated depending on two factors, the transmission path and loading condition [19]. Therefore the vibration signal is typically demodulated to extract the frequency of these impulses. Equations for calculation of bearing faults frequencies have been reported widely in the literature [13;53; 54]. These equations assume no slip, however, in operation there is some degree of slip and this why the bearing faults frequencies vary by $1 \%$ to $2 \%$ of the calculated value. It is this slip that facilitates the separation of the gear and bearing vibration components [8], the latter known as the nondeterministic component of the measured vibration.

The deterministic part of the signal is usually related to gear and shaft speeds [14]. Such periodic events are related to kinematic forces induced by the rotating parts such as meshing forces, misalignment and eccentricity [22]. In some cases the deterministic part of the vibration signal cannot be identified due to speed variation, and therefore it essential to resample the signal to the angular domain in order to track speed variation [22; 55]. The deterministic part of the signal can be used for diagnostics of gear and shaft faults.

Similarly, the AE signal can be decomposed into deterministic and non-deterministic parts, which is related to gear and bearing signals. However, processing of $A E$ signals is computationally expensive and only relatively short time series $A E$ signatures can be processed [51]. In application to diagnosis of machine faults, simple AE parameters are typically employed, such as rms, kurtosis, AE counts [41] and demodulation [38]. More recently the use of Spectral Kurtosis and adaptive filters have been employed to facilitate the diagnosis of machine faults with $\mathrm{AE}[34 ; 39 ; 40]$.

\section{Signal processing and data analysis}

Bearing and gear fault identification involves the use of various signal processing algorithms to extract useful diagnostic information from measured vibration or AE signals. Traditionally analysis has been grouped into three classes; time domain, frequency domain and timefrequency domain. The statistical analysis techniques are commonly applied for time domain signal analysis, in which descriptive statistics such as rms, skewness, and kurtosis are used 
to detect the faults [56; 57]. A fast Fourier transform (FFT) is commonly used to obtain the frequency spectra of the signals. The detection of faults in the frequency domain is based on identification of certain frequencies which are known to be typical symptoms associated with bearing or gear faults. The time-frequency domain methods are composed of the short-time Fourier transform (STFT) [58], Wigner-Ville [56], and wavelet analysis [59; 60]. The use of these detection techniques are feasible for applications where a single component is being monitored however for applications that include several components, such as gearboxes, it is essential to employ separation algorithms.

For this study, the vibration and $A E$ signals acquired were processed by firstly employing an adaptive filter algorithm to estimate the deterministic component of the signal. Secondly, spectral kurtosis was used to estimate the filter characteristics of the deterministic signal for envelope analysis. Lastly, a frequency spectrum of the enveloped signal was determined. The signal processing procedures are summarised in Figure 1, description of these algorithms are shown in the following section.

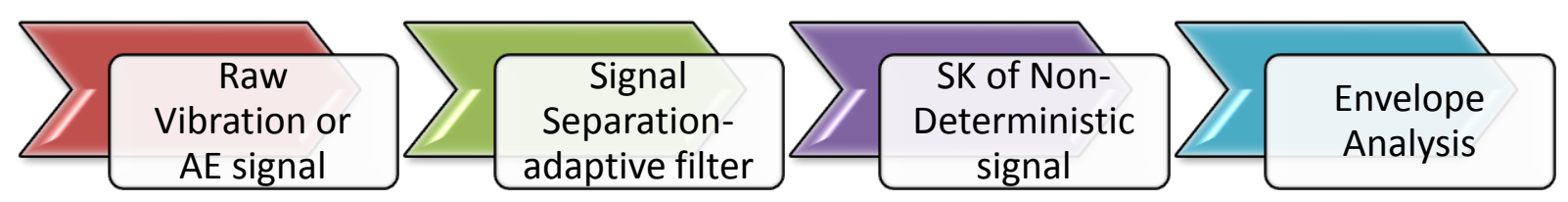

Figure 1 Signal processing algorithms flow chart

\subsection{Adaptive filter}

An adaptive filter is used to model the relationship between two signals in an iterative manner; the adaption refers to the method used to iterate the filter coefficient. The adaptive filter solution is not unique; however the best solution is that which is closest to the desirable 
response signal [61]. FIR filters are more commonly used as adaptive filters in comparison to IRR filters [62].

The adaptive filter principle is based on Wold theorem which proposes that the vibration signal can be decomposed into two parts, deterministic $\mathrm{P}(\mathrm{n})$ and random $\mathrm{r}(\mathrm{n})$. This decomposition process can be represented by the following formula [32] :

$$
x(n)=P(n)+r(n)
$$

The process of separation begins by applying adaptive noise cancellation (ANC). The fundamentals of this method has been detailed, and the general layout of the ANC algorithm is shown in Figure 2 [32; 63].

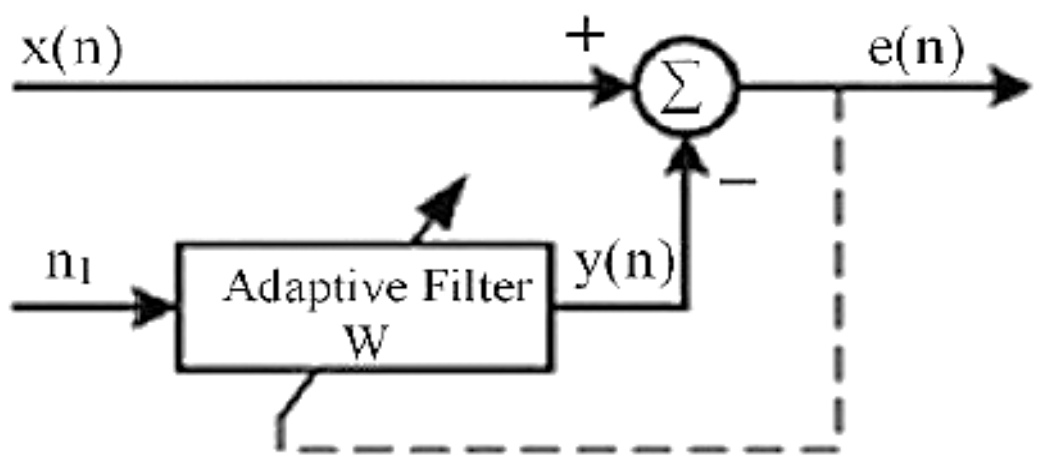

Figure 2 ANC algorithm [32;63]

In application of the self-adaptive Least Mean Square (LMS) algorithm, the reference signal in the application of ANC algorithm is replaced by a delayed version of the input signal. In this algorithm, the signal is filtered using a Wiener filter, the coefficients of which should be updated for each step. As a consequence, feedback from the filter output is required to estimate the filter coefficients. This process is repeated for each filter step until the prediction error reaches the minimum value. The adaptive filter is a special case of FIR filter expressed by the following relation:

$$
Y_{i}=\sum_{i=0}^{n-1} h_{i} * x(t-i)
$$


Where, $h_{\mathrm{i}}$ is the filter coefficient, $\mathrm{x}(\mathrm{t}-\mathrm{i})$ is corresponding sample of time series signal, and $\mathrm{n}$ denotes the number of samples in the input signal.

Equation (2) is similar to linear prediction, however the difference is the filter coefficient in this case is estimated recursively based on Least Mean square Error (LMS).

In order to optimize filter parameters and minimize prediction error, the prediction error $\varepsilon_{\mathrm{t}}$ should be estimated by [63]:

$$
\varepsilon_{\mathrm{t}}=\mathrm{d}_{\mathrm{t}}-\mathrm{h}_{\mathrm{i}} * \mathrm{x}(\mathrm{t}-\mathrm{i})
$$

where, $d_{t}$ denotes the desirable signal. The filter coefficient should be adjusted to minimize this error function. The error might be random in distribution and as such the expectation of the square error signal is used. This leads to the cost function presented in equation (4), which should be minimised in order to find the optimum filter coefficients. This function is defined by:

$$
\mathrm{E}(\mathrm{MSE})=\mathrm{E}\left(\frac{1}{2} \sum\left(\mathrm{d}_{\mathrm{t}}-\mathrm{h}_{\mathrm{i}} * \mathrm{x}(\mathrm{t}-\mathrm{i})\right)^{2}\right)
$$

To optimize the mean square error, the cost function should be minimized.

$$
\frac{\partial \mathrm{MSE}}{\partial \mathrm{h}}=0
$$

The solution of this optimization problem leads to the estimation of the optimum coefficients, this solution known as the Wiener-Hopf filter equation [33]:

$$
\mathrm{h}_{\mathrm{opt}}=\left[\mathrm{R}_{\mathrm{xx}}\right]^{-1} \mathrm{R}_{\mathrm{dx}}
$$

where, $\mathrm{R}_{\mathrm{xx}}$ is the autocorrelation function of the input signal, and $\mathrm{R}_{\mathrm{dx}}$ is cross-correlation between input signal and desirable output. However, in the case of the gearbox signal there is no reference signal; instead a delayed version of the input signal is used, therefore the Weiner-Hopf equation is written as:

$$
\mathrm{h}_{\mathrm{opt}}=\left[\mathrm{R}_{\mathrm{xx}}(\mathrm{t}-\Delta)\right]^{-1} \mathrm{R}_{\mathrm{xx}}
$$

where, $R_{x x}(t-\Delta)$ is the autocorrelation of the delayed signal.

In practice, the filter size is very large and the Weiner-Hopf equation is difficult to solve. As a result, an approximated adaptive LMS algorithm is proposed [61], such that the coefficients are updated by: 


$$
\mathrm{h}_{\mathrm{t}+1}=\mathrm{h}_{\mathrm{t}}+2 \mu \mathrm{x}(\mathrm{t}) \varepsilon
$$

In which $\mathrm{h}_{\mathrm{t}+1}$ denotes the updated filter coefficient, and $\mu$ denotes the step size of the filter. This latter parameter should be selected carefully; the larger the step size, the faster the convergence, whilst a smaller step size leads to more accurate prediction, but the computation cost is high. The range of step size selection can be expressed as [62]:

$$
0<\mu<\frac{1}{\lambda_{\max }}
$$

Where, $\lambda_{\max }$ is the maximum value for eigenvalue for autocorrelation $\mathrm{R}_{\mathrm{xx}}$. For a step size greater than $\frac{1}{\lambda_{\max }}$, the convergence speed can be reduced.

\subsection{Envelope analysis and Spectral Kurtosis}

Envelope analysis is applied extensively in vibration analysis for the diagnosis of bearings and gearboxes $[9 ; 15 ; 19]$. As impacts due to the defects excite resonance at higher frequencies, it is possible to identify the frequency of the impacts with the use of envelope analysis. In application, the vibration signal is filtered at high frequencies (structural resonance frequencies) and then the signal is passed through an envelope detector and a low pass filter. The enveloped signal is either presented in the time domain or transformed into the frequency domain in order to identify fault frequency components [64]. In order to detect fault signatures it is important to select filter parameters carefully [65]. In addition, Spectral Kurtosis (SK) has been applied to select such filter parameters [35; 66]. The basic principle of the SK method is to determine the Kurtosis at different frequency bands in order to identify the energy distribution of the signal and to determine where the high impact (transient) energy is located in the frequency domain. Obviously the results obtained strongly depend on the width of the frequency bands $\Delta f$ [36]. The Kurtogram [25] is a representation of the calculated values of the SK as a function of $f$ and $\Delta f$. However, exploration of the entire plane $(f, \Delta f)$ is a complicated computational task, though Antoni [36] suggested a methodology for the fast computation of the SK, On identification of the frequency band in which the SK is maximized (Kmax), this information can be used to design a filterthat extracts the part of the signal with the highest level of impulsiveness. Antoni et al. [36] demonstrated how theoptimum filter which maximizes the SNR is a narrow-bandfilter at the 
maximum value of SK. Therefore, the optimal central frequency fc and bandwidth $\mathrm{Bf}$ of the band-passfilter are found as the values of $f$ and Df which maximizethe kurtogram. The filtrated signal can be finally used to perform an envelope analysis.

\section{Experimental Setup}

\subsection{Lab scale test rig}

In order to understand, test and validate the performance of acoustic emission as a sensing technique, a range of lab-scale tests were performed. By seeding faults in a representative setup it was possible to identify the detection potential of $A E$, for a range of faults, in a controlled condition, particularly in comparison with more established vibration techniques. To provide the most representative test conditions with which to study a helicopter gearbox, an existing rig was heavily modified as shown in Figures 3 and 4,. The rig uses three gears, an input gear, an idler gear and an output gear, to approximate a single planet of an epicyclic setup. The chosen gear teeth give the asynchronous rotation that is typical of epicyclic configurations. The input gear is driven by a fixed speed motor, and the output gear is loaded by a variable dynamometer. The motor output uses a flexible spider coupling to drive an input shaft, which is supported by two SKF SYJ507 bearings, shown in Figure 5 below. The end of the input shaft passes into a steel-walled oil sump, with a clear perspex lid with gasket. On the end of the input shaft, a 17 tooth, module 4, $68 \mathrm{~mm}$ pitch diameter gear is located by a parallel key in the shaft and a corresponding notch in the gear, and is retained by a nut and secondary locknut. The gear is $25 \mathrm{~mm}$ thick and is made of case-hardened steel. This setup was intended to economically best replicate a single MGB planet gear in a research environment.The idler gear was allowed to rotate about a fixed idler shaft by two taper roller bearings. The non-rotating idler shaft supports an 18 tooth, module $4,72 \mathrm{~mm}$ pitch diameter idler gear which is driven by the input shaft and gear. Rotation of the gear relative to the idler shaft is facilitated by a pair of taper-roller bearings, type SKF $32005 \mathrm{X} / \mathrm{Q}$, which allow some pre-load to be applied. The bearing outer races are a press-fit into the gear and they are retained by a threaded ring with a locking bolt which tightens against the shaft. The bearings were lubricated using multi-purpose lithium grease with a working temperature range of $-15^{\circ} \mathrm{C}$ to $135^{\circ} \mathrm{C}$. The shaft caps were tightened to $15 \mathrm{Nm}$ torque.. The gearbox was driven by electric motor $(15 \mathrm{~kW})$ at a rotation speed of $1500 \mathrm{rpm}$. A load of $10 \mathrm{~kW}$ was applied by a dynamometer. Synthetic AeroShell Turbine Oil 555 was employed for the gearbox lubrication, see table 1 . 


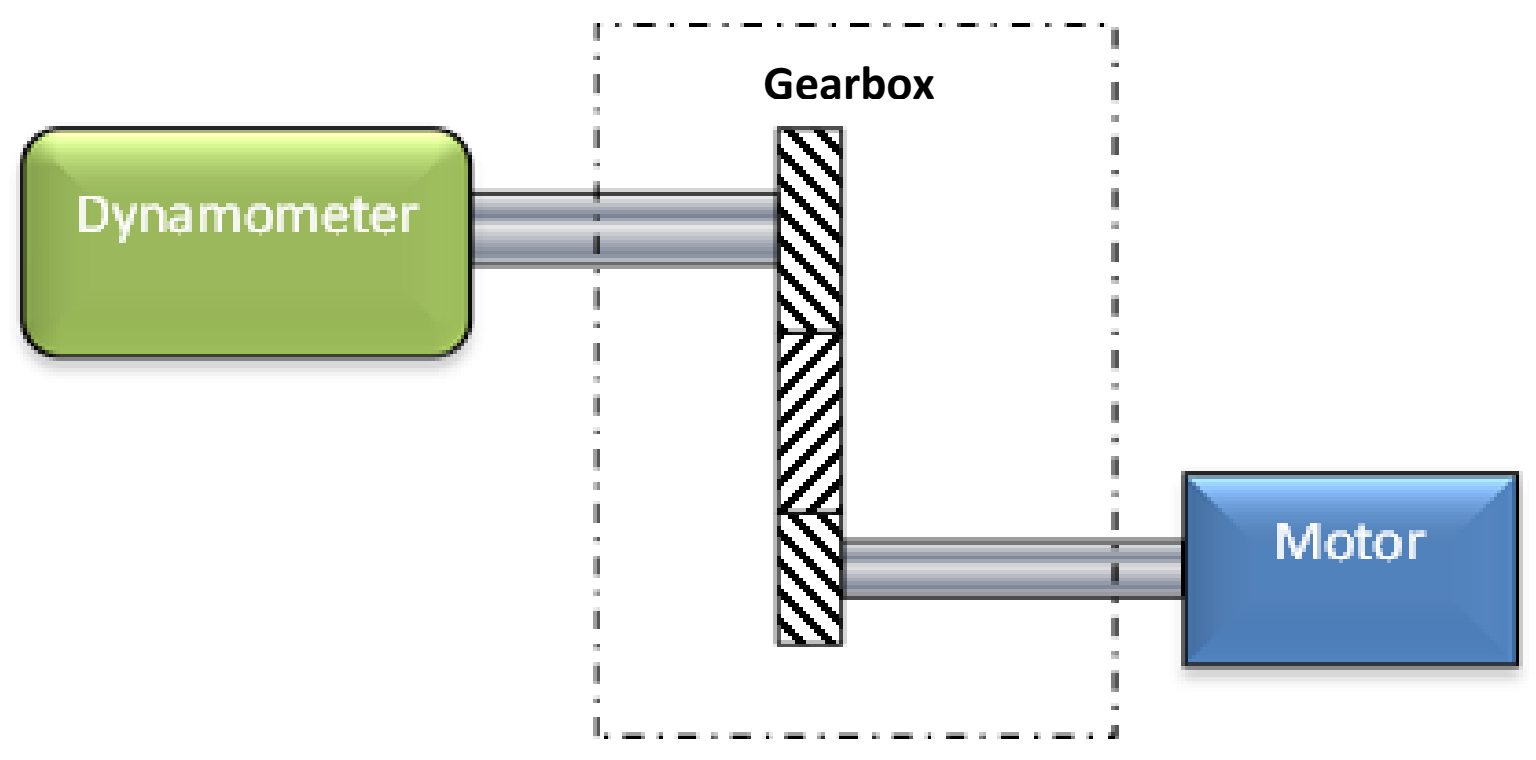

Figure 3 Test rig schematic

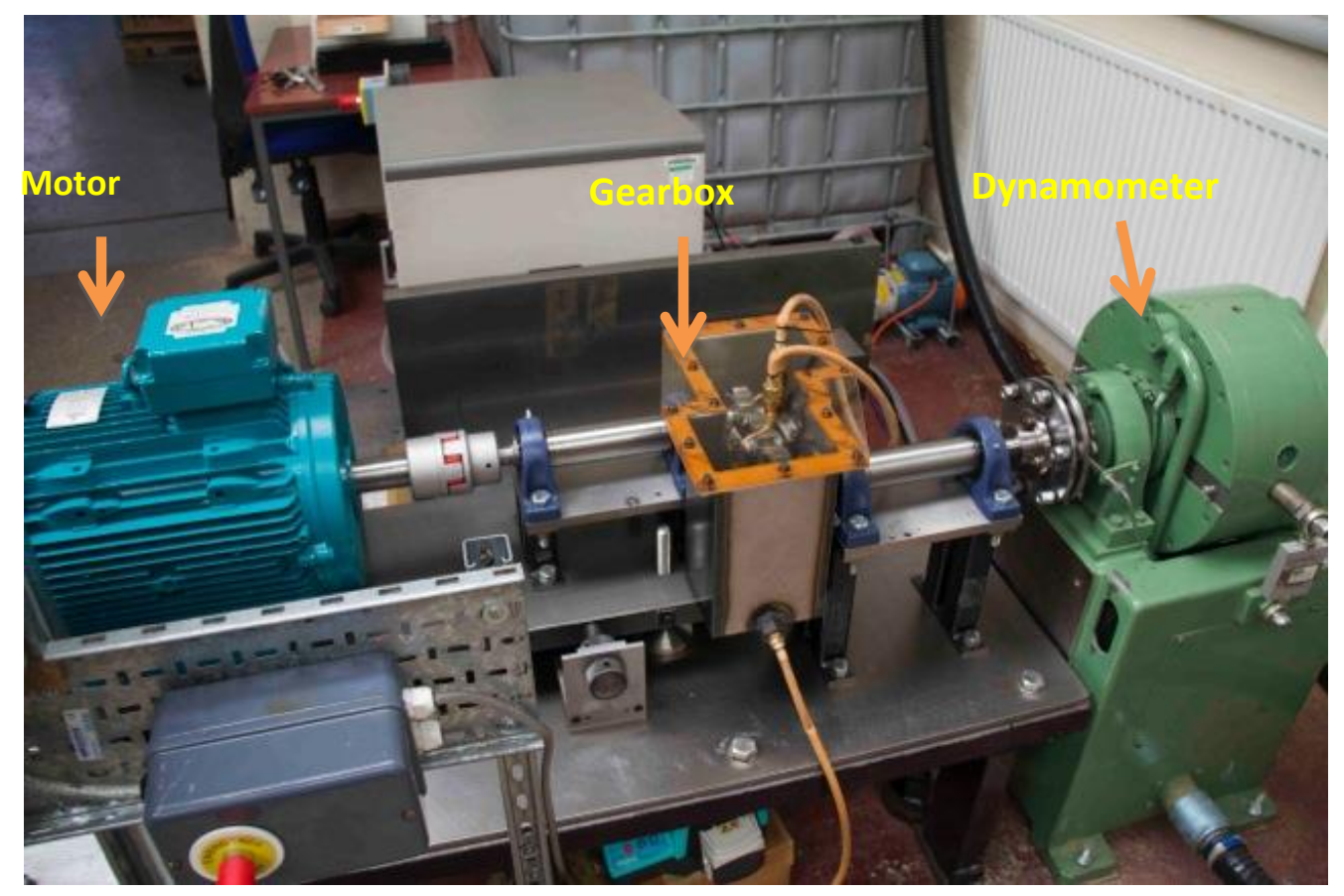

Figure 4 Test rig layout

Table 1 Gears specification

\begin{tabular}{|l|c|c|c|}
\hline Gear & Input gear & Idler gear & Output gear \\
\hline Number of teeth & 17 & 18 & 19 \\
\hline
\end{tabular}




\begin{tabular}{|l|l|c|}
\hline Module (mm) & \multicolumn{2}{|c|}{4} \\
\hline Pitch diameter (mm) & \multicolumn{1}{|c|}{68} & \multicolumn{1}{|c|}{72} \\
\hline Pressure angle ( $\left.{ }^{\circ}\right)$ & 25 & 97 \\
\hline Facewidth (mm) & 90 & $\begin{array}{l}|c| \\
\text { EN36c steel, ground case harden to give a case depth core } \\
\text { Material }\end{array}$ \\
\hline Oil & Ester synthetic, Kinematic viscosity@ $-40^{\circ} \mathrm{c} 11000 \mathrm{~mm}^{2} / \mathrm{s}$ \\
\hline
\end{tabular}

The gears were supported by a single row deep groove ball bearings (SKF SYJ 507) whilst the idler gear bore was machined to accommodate two single row tapered roller bearing (SKF 32005 X/Q). As such the outer race of the bearing was in direct contact with the gear inner bore and the outer race rotated with the gear whilst the inner race was stationary, similar to planetary gears employed in epicyclic gearboxes, see figure 4.

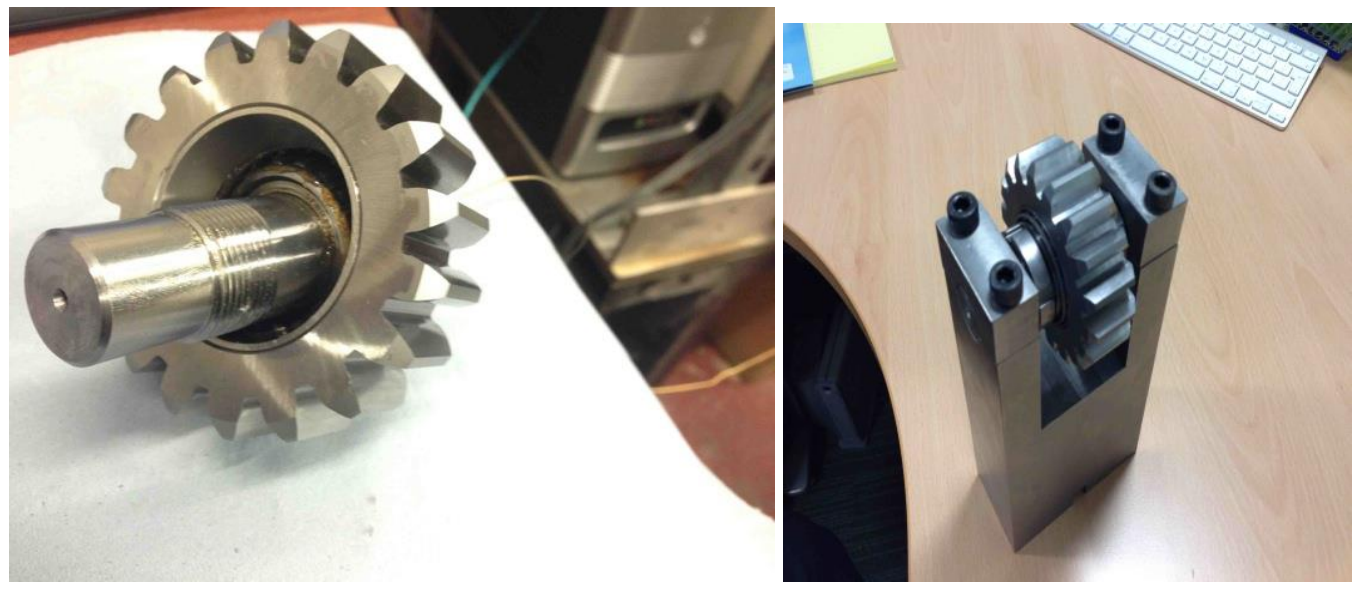

Figure 5 Idler gear and bearing assembly

Bearing faults were seeded on the idler gear bearing to simulate a planet gear bearing fault. Outer race bearing defects of different sizes were seeded. In total three fault conditions were considered, which included fault free condition, a small defect of $2 \mathrm{~mm}$ diameter and $0.5 \mathrm{~mm}$ depth and a large defect simulated as a slot across the bearing outer race $(2 \mathrm{~mm}$ wide and $1 \mathrm{~mm}$ deep); see figure 6 . To aid diagnosis, all characteristic vibration frequencies were determined, see Table 2. These included the shafts speed with its harmonics and the bearing defects frequencies. The bearing defect frequencies were calculated and referenced to the rotating speed. Vibration data was acquired with a triaxial accelerometer (type PCB 
Piezotronics 356A03) at a sampling frequency of the $51.2 \mathrm{kHz}$. The accelerometer had an operating frequency range of $2 \mathrm{~Hz}$ to $8 \mathrm{kHz}$ and resonance frequency of $50 \mathrm{KHz}$. The acquisition system employed was a National Instruments (NI) CDAQ-9172 chassis fitted with a 9234 module. A 60 second sample was recorded for each fault case. The accelerometer was installed on the idler shaft, which runs through the idler gear, as this was not rotating, see figure 7. The $Y$-axis of the tri-axial accelerometer arrangement was oriented parallel to idler shaft direction; the X-axis refers to the vertical axis perpendicular to the idler shaft axis, and the Z-axis is the horizontal axis perpendicular to the idler shaft axis, see figure 7 . In addition, a Physical Acoustics Corporation (PAC) PICO commercial sensor was placed adjacent to the vibration sensor, see figure 7. AE data was acquired at a sampling rate of 5 $\mathrm{MHz}$ using a PAC PCl-2 card and a 2/4/6 pre-amplifier, with gain set at $40 \mathrm{~dB}$.
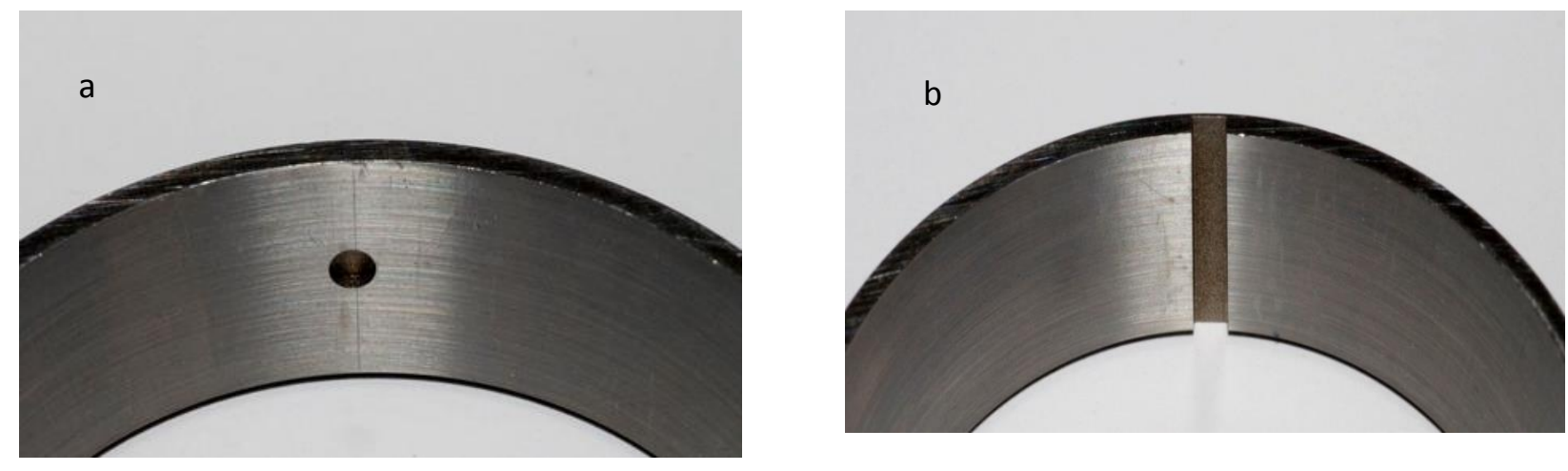

Figure 6 Seeded fault cases (a) small defect (b) large defect

Table 2 Spectrum frequency components

\begin{tabular}{|l|l|}
\hline Component & Frequency $\mathbf{( H z )}$ \\
\hline Motor Shaft & 25 \\
\hline Intermediate shaft & 23.6 \\
\hline Dynamometer shaft & 22.4 \\
\hline Gear mesh Frequency GMF & 425 \\
\hline Outer race Defect frequency & 192 \\
\hline
\end{tabular}




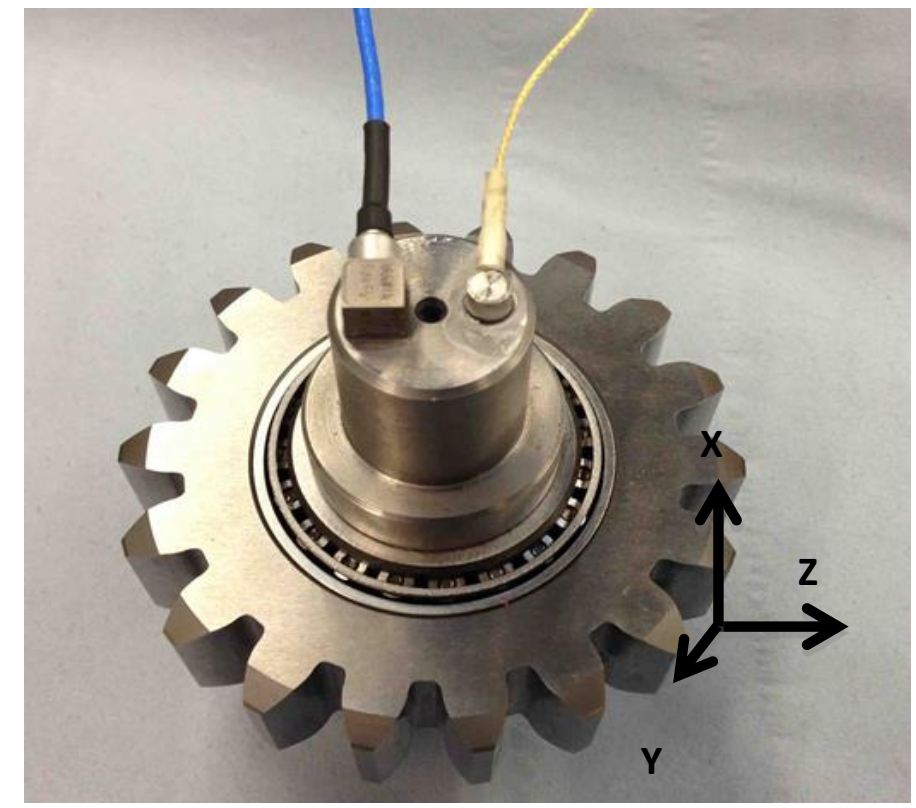

Figure 7 Vibration (left) and AE (right) sensor location

\subsection{AE WIRELESS SYSTEM}

A new approach was developed to wireless transmit of $A E$ signals from source to reciever.The system employed a "homodyne" (same- frequency) receiver with a "modulated backscatter" communications link, to pass the analogue signal across the wireless link. Operation at $13.56 \mathrm{MHz}$ allows the use of magnetic coupling, where the "antennas" are two tuned loops of wire or pipe. Such coupling is termed "near field" and relies purely on magnetic coupling, as seen in a conventional transformer for AC mains. The magnetic loop does not produce a TEM "propagating" wave, as in a normal broadcast transmitter. By using two parallel, coaxial coils in close proximity, the coupling remains consistent as one coil rotates with respect to the other.

"Modulated backscatter" is a technique that relies on periodic damping of the resonant circuit of the rotating loop. When magnetically coupled to a receiving loop, the modulation may be detected. In contactless cards, the data is transmitted digitally by modulating a carrier signal with a square wave. However, in this application, there was a need to transmit a linear analogue signal over a bandwidth extending from $100 \mathrm{kHz}$ to $1 \mathrm{MHz}$, to preserve the shape of the sensor time domain waveform. 
In order to test the approach described above, a prototype system was constructed. This consisted of two coils (to replicate a fixed and rotating coil) with one attached to a sensor conditioning board, which accepts a signal input, and the other attached to a demodulator producing an output signal.

A high stability oscillator is used as the transmit source and to ensure the oscillator is not adversely loaded, a buffer amplifier is used to drive a power amplifier producing approximately 1 Watt of RF output into the illuminator coil. The buffer amplifier is also required to ensure that the carrier signal has no backscatter modulation present on it, as a pure sine wave carrier is needed as a reference in the coherent demodulator.

\subsubsection{Coherent demodulator and filter}

The receive input from the illuminator coil tap is fed to a demodulator IC. The baseband output from the demodulator is buffered and fed to a low pass filter to drive a final amplifier. The carrier input to the demodulator is obtained by a connection to the crystal oscillator, through a phase shift network. The carrier phase shifter is necessary to correctly align the carrier phase with the backscattered phase, to obtain the highest baseband output possible from the demodulator IC.

\subsubsection{Rotating coil and sensor}

The receive loop is tuned by a capacitor to bring it to resonance just above $13.56 \mathrm{MHz}$. A rectifier produces a dc voltage, which is smoothed for an opamp. The opamp has a gain bandwidth product of $18 \mathrm{MHz}$ and draws $3 \mathrm{~mA}$ from a $3.6 \mathrm{~V}$ supply. The sensor output is fed into the high impedance input of the opamp to avoid loading the sensor output. The output feeds a low pass trap to ensure the very high levels of $13.56 \mathrm{MHz}$ do not appear at the amplifier's output pin, but pass the $1 \mathrm{MHz}$ sensor signal to the varactor diode. A small dc voltage is provided to bias the varactor into its most linear region. With no sensor signal applied to the varactor (just the bias voltage), its capacitance brings the resonance of the circuit to precisely $13.56 \mathrm{MHz}$ 


\subsubsection{Transmit loop (fixed part)}

To set the coil's quality factor $(Q)$, a resistor is used which also allows a tap-off for the backscattered field. The $Q$ factor has to be adjusted to allow sufficient $Q$ for the transmission of power, but not too high to limit the system bandwidth, which would cause a drop off in the response at $1 \mathrm{MHz}$.

\subsubsection{Set up and test of the system}

After installation the system needs to be tuned as the spacing between the coils changes their mutual coupling, $Q$ and bandwidth and this alters the values needed on the matching network. By tuning components on the fixed coil circuitry, the flattest response, at the expense of signal amplitude can be achieved.

When installing the sensor board against a metal object, it was necessary to use ARC WAVE-X to avoid detuning the coils. This is a flexible EMI/RF absorber, which allows the coils to be close to metal without being detuned. Investigating the frequency behavior of the lab-scale system, the system behaves in a broadly linear way in the $100 \mathrm{kHz}$ to $1 \mathrm{MHz}$ range. The only known shortcoming of the lab-scale system is the effect of dispersion on the sensor signal, which will be displayed in the time domain. Dispersion, sometimes known as non-linear group delay, results when different frequency components in the baseband signal are delayed by different times as they pass through the circuitry. The main cause of dispersion is the sharp phase response of the tuned resonator consisting of the two coils and their mutual coupling. The high $Q$ (and thus dispersive response) is needed to transfer power efficiently, otherwise much of the RF power would be wasted in the series resistor at the base of the coil.

If the dispersion is consistent, then it can be corrected using software, by delaying different frequencies by appropriate amounts and then reconstructing the time signal.

\subsection{FULL-SCALE TESTING}

In order to test and validate the approach outlined by the lab-scale testing, it was necessary to perform full-scale testing of the acoustic emission and wireless transmission concept. Whilst the lab-scale approach tentatively proved the concept, many of the issues surrounding new techniques are only revealed when it is implemented at full-scale. 
For this phase of testing, an SA 330 Puma gearbox was acquired. Whilst this gearbox is an older design, it was the basis of the design of the current EC225 main gearbox, and shares many of the same design features. Most importantly for this project, it has a final two-stage epicyclic reduction utilizing a combined planet gear / outer bearing race design. (see Figure 11).

\subsubsection{AE sensor selection}

Having selected $A E$ as the detection mechanism, it was necessary to select a sensor for use inside the MGB and Figure 8 shows the range chosen for the project. All of the sensors considered required signal conditioning and/or pre-amplification. Research by Pickwel [67] showed that the development of a functioning micro AE sensor (approximately $20 \mu \mathrm{m}$ thick) was possible and comparison with commercial AE sensors provided some confidence in the performance of the sensor. However, this research work focused more on the design and physical production of these sensors rather than the detail of their performance.

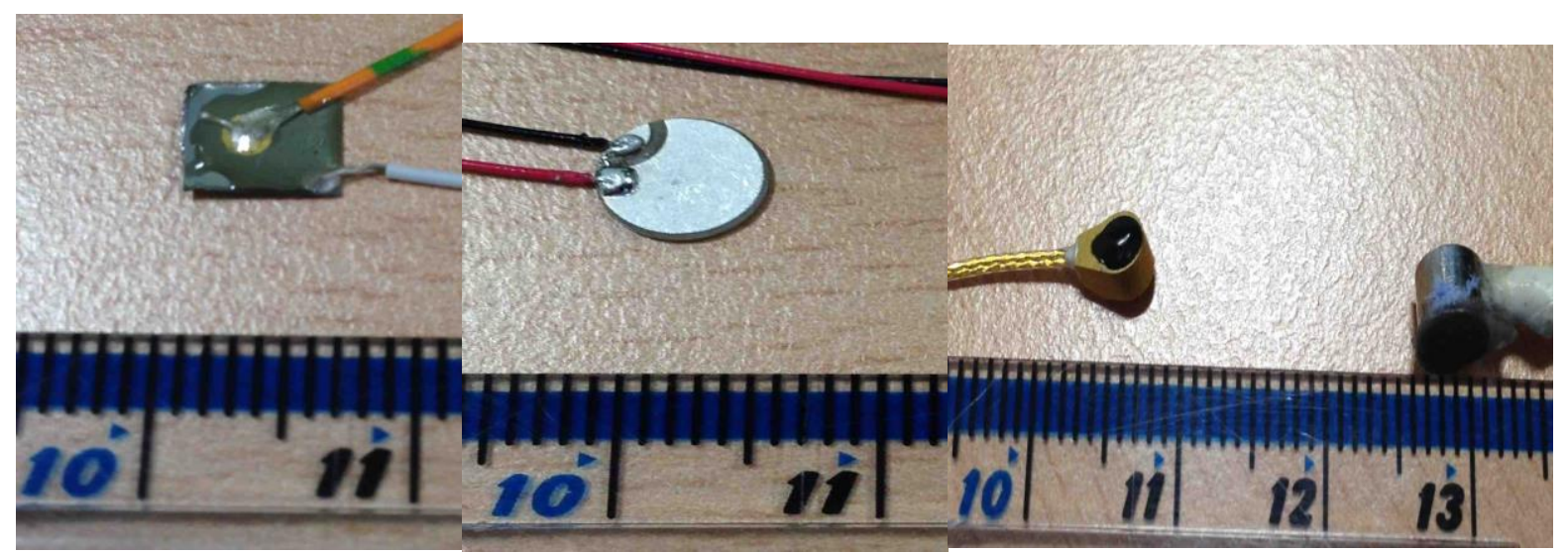

Figure 8 Potential AE sensors (L-R) micro, PWAS, s9225 and Pico

Three AE sensors were considered for this application;a piezoelectric-wafer active sensor (PWAS) [68], the s9225 sensor, a miniature (3.6 $\mathrm{mm} \times 2.4 \mathrm{~mm}$ ) acoustic emission sensor from Physical Acoustics weighing less than 1 gram, with an operating range from $300 \mathrm{kHz}$ to $1 \mathrm{MHz}$ and lastly, a Physical Acoustics Pico sensor, is a miniature $(5 \mathrm{~mm}$ diameter, $4 \mathrm{~mm}$ height) acoustic emission sensor weighing less than 1 gram. This was the sensor used in the lab-scale testing. 
There was a need to balance reliability and stability against the potential damage if released. The Pico is a reliable COTS sensor, but would cause significant damage if released into a planet bearing. The micro sensor is the smallest of the sensors but is experimental and susceptible to noise. Therefore, a comparison between the PWAS and s9225 sensors was conducted on the lab-scale rig, with the PWAS proving more effective. This sensor was used for the full-scale test programme. An additional feature of the PWAS sensor is its very broadband performance (from low kilohertz up to Megahertz). This means that it is able to function to detect more traditional vibration frequency ranges as well as $A E$ ranges.

\subsubsection{Experimental setup}

A test programme was devised consisting of tests in three conditions - an undamaged planet bearing; a heavily damaged planet bearing; and a slightly damaged planet bearing. The different conditions were achieved by swapping a planet gear between each test. Each of these three conditions was tested at a range of loads.

The bearing faults were seeded on one of the planet gears of the second epicyclic stage. the damage simulated as a natural spalling around half of the circumference and an outer race, see Figure 9

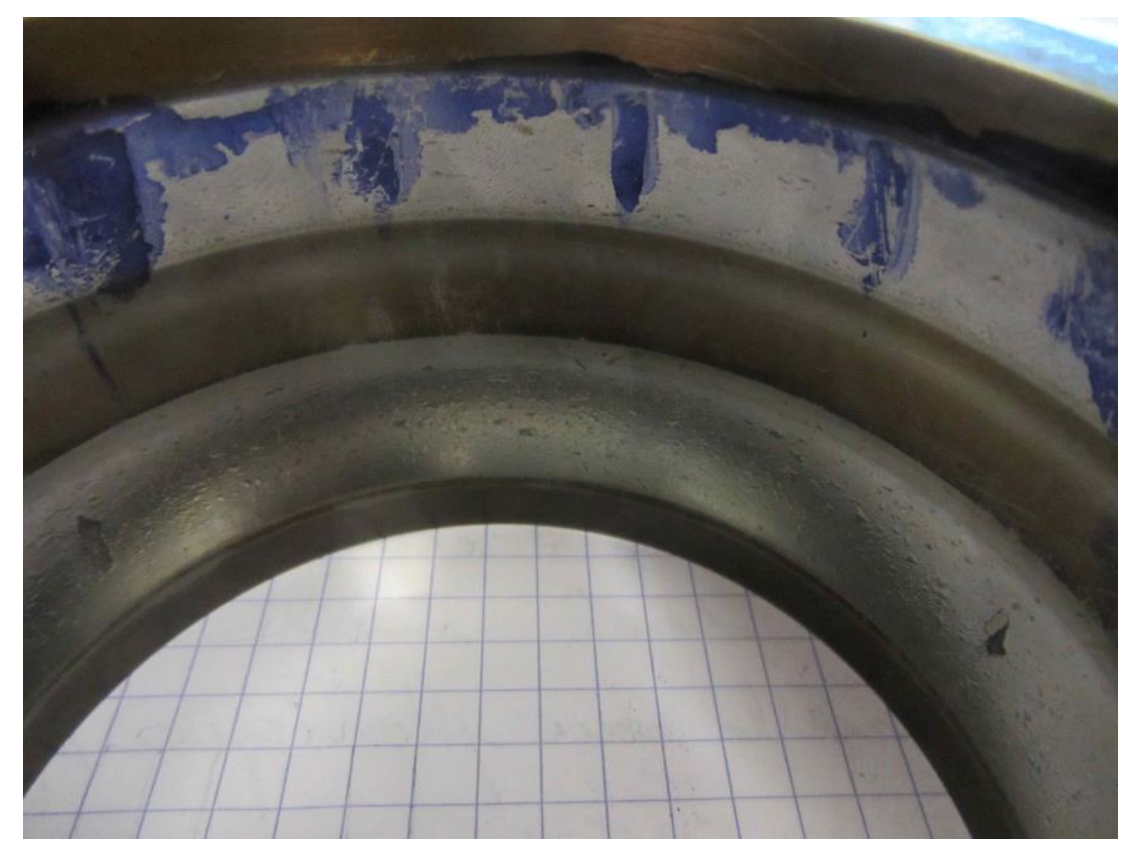

Figure 9 Natural slight Spall damage seeded on planet gear bearing

In its current form, the wireless transfer system is only able to support a single sensor, and 
therefore it was necessary to select a location at which to attach the sensor. One of the restrictions to the positioning of the sensor was the need to keep the sensor clear of the main upper face of the planet carrier to allow it to be used as pressure face when changing the planet gears. The sensor was bonded in a position on the 'dish' of the planet carrier, as shown in Figure 10 and Figure 11 below.

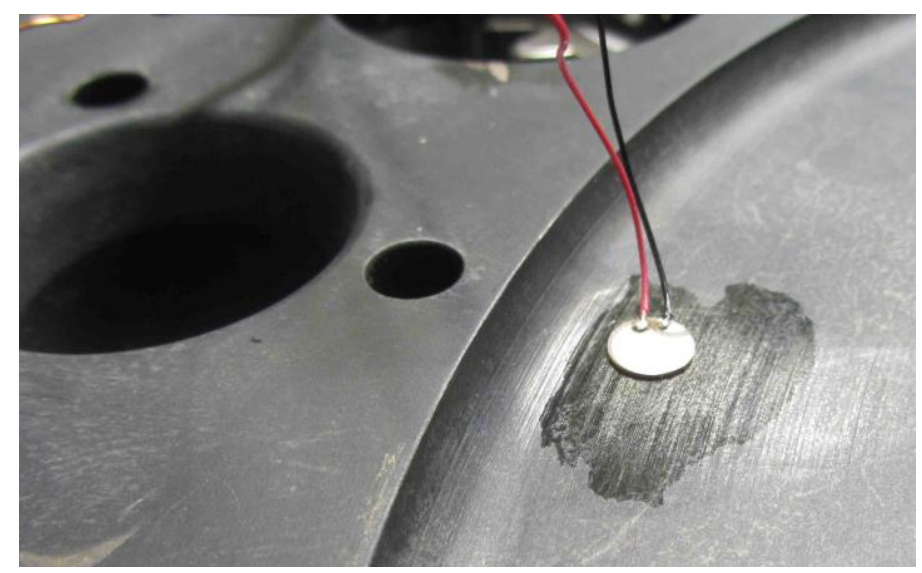

Figure 10 Sensor position on dish of planet carrier

For the full-scale wireless system, the prototype system was modified and rebuilt for operation inside the Puma gearbox. Whilst the principles and transfer mechanisms of the lab-scale design remained the same, there were changes to most aspects of the system. 
One of the most significant changes from the lab-scale system was that the space available to mount coaxial coils on the planet carrier and the gearbox casing is limited. The full-scale system comprised two single turn brass coils of approximately $400 \mathrm{~mm}$ diameter which were cut to size using water jets for accuracy. The stationary (upper) coil was suspended from two clamping rings which were attached to the top case of the gearbox with a spacer through the holes to retain location. The moving (lower) coil was attached to a circular mounting ring which was, in turn, mounted on top of the oil caps on the planet carrier (see Figure 11).

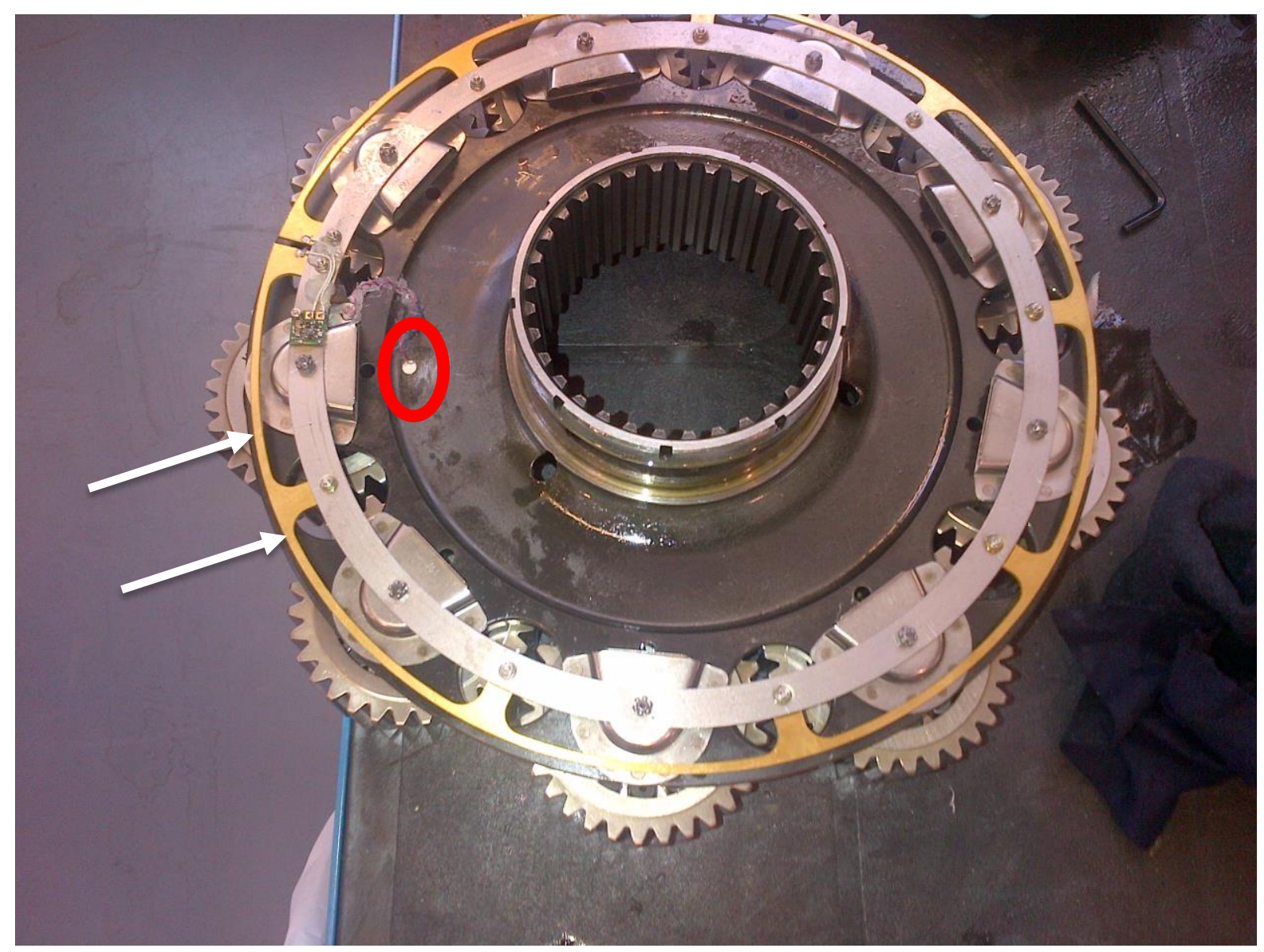

Figure 11 Moving coil mounted on the planetary carrier (coil arrowed, sensor circled)

Figure 12 shows the two coils in position before the top cover was pressed onto the planet carrier. Electrical isolation of the coils from the mounts and surrounding metallic structure was achieved through the use of nylon washers and bushes. The main electrical difference between the lab-scale coils and the full-scale coils is their proximity to metal, and in particular, the mounting ring which forms a "shorted 
turn". The proximity causes a drastic reduction in inductance, which then requires an increase in loading capacitance to maintain tune at $13.56 \mathrm{MHz}$. In addition to the reduction in inductance comes a large reduction in the $Q$ factor of the coupled circuit. Fortunately, the electrical power transfer requirement in the gearbox was significantly reduced compared to the prototype, as the spacing between the coils was relatively close. This meant that even with reduced $Q$, there was enough power transferred to run the opamp buffer circuit. One advantage of reduced $Q$ factor is that dispersion is reduced in the baseband signal. This is because the steepness of the phase/frequency response is reduced in the vicinity of the resonance at 13.56 $\mathrm{MHz}$.

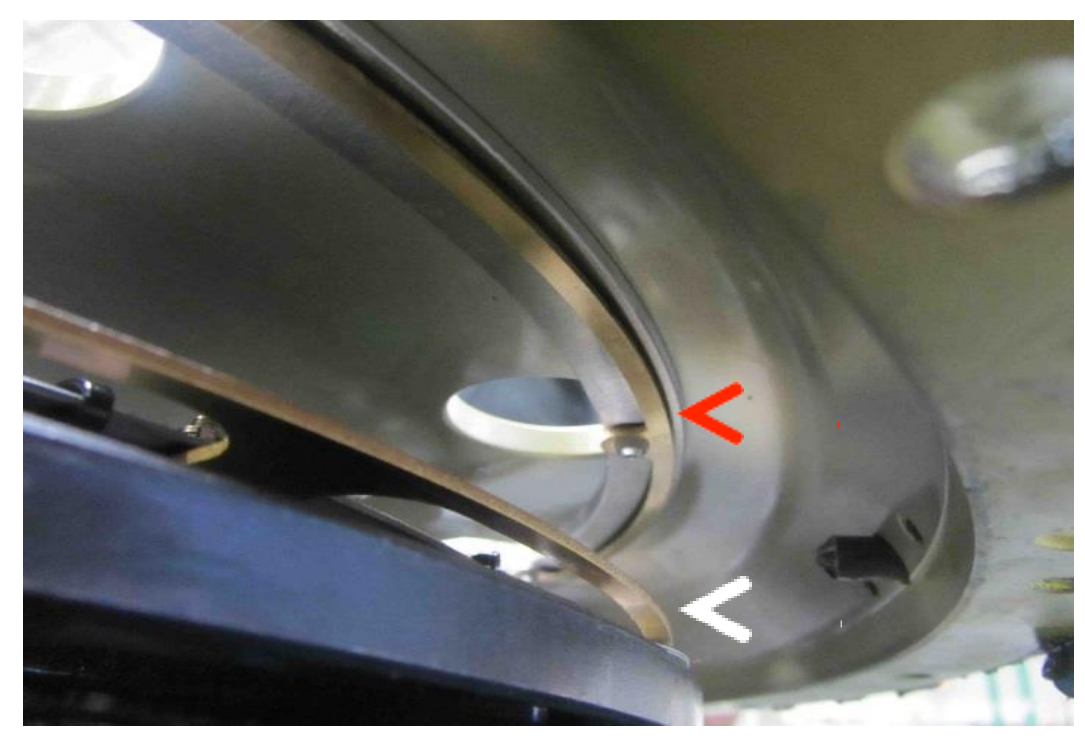

Figure 12 Coils in position before re-joining top cover (static coil red arrow, moving coil white arrow)

Once installed in the gearbox, it was possible to temporarily attach a signal generator to the sensor boards. By comparing the input signal with the output signal of the system transmitted through the coils, the time delay of the system was measured. From $100 \mathrm{kHz}$ to $1 \mathrm{MHz}$, there was very little delay variation with frequency - the system is behaving as a length of cable - providing about $1 \mu \mathrm{s}$ delay at all frequencies. This means that in this range it is linear phase and nondispersive i.e. there is no variation in wave speed with frequency. Below $100 \mathrm{kHz}$ there is significant dispersion, but since most 'low' frequency analysis techniques 
ignore phase, this is not a significant limitation.

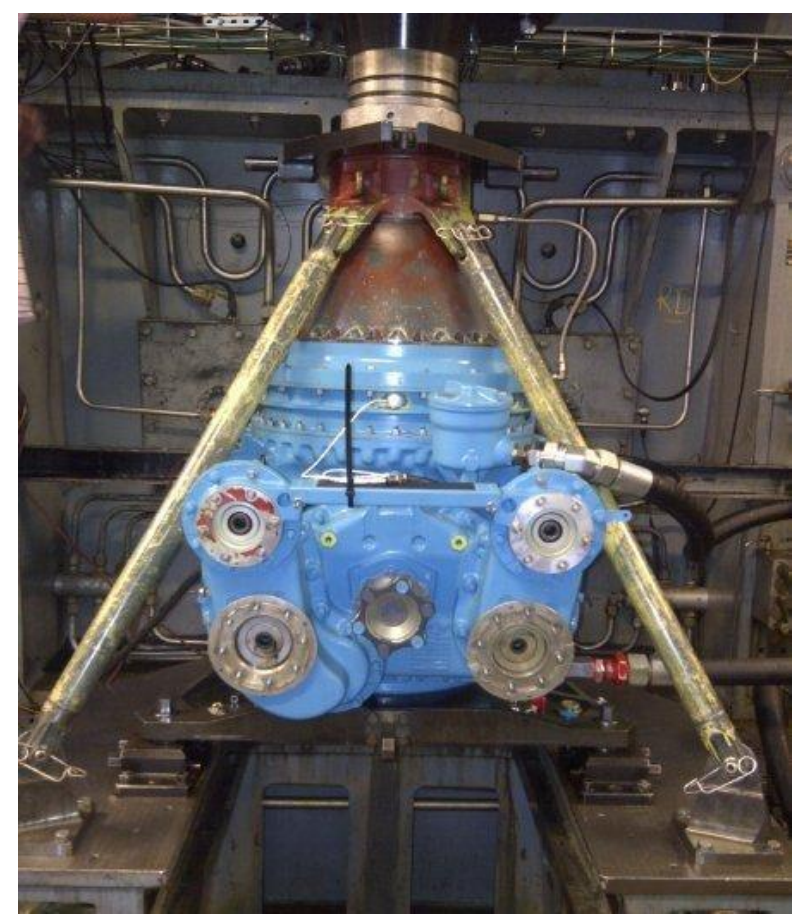

Figure 13 MGB installed on the test bench

\section{$5 \quad$ Lab scale Observations}

\subsection{Vibration Observations}

Figure 14 (a) shows the vibration signature prior to signal separation of the deterministic components for the small defect test condition. Figure 14 (b) shows the nondeterministic component of the signal after the seperation, highlighting the fact that no periodic impact shocks were evident with the small defect, the later also applied to the large defect condition.

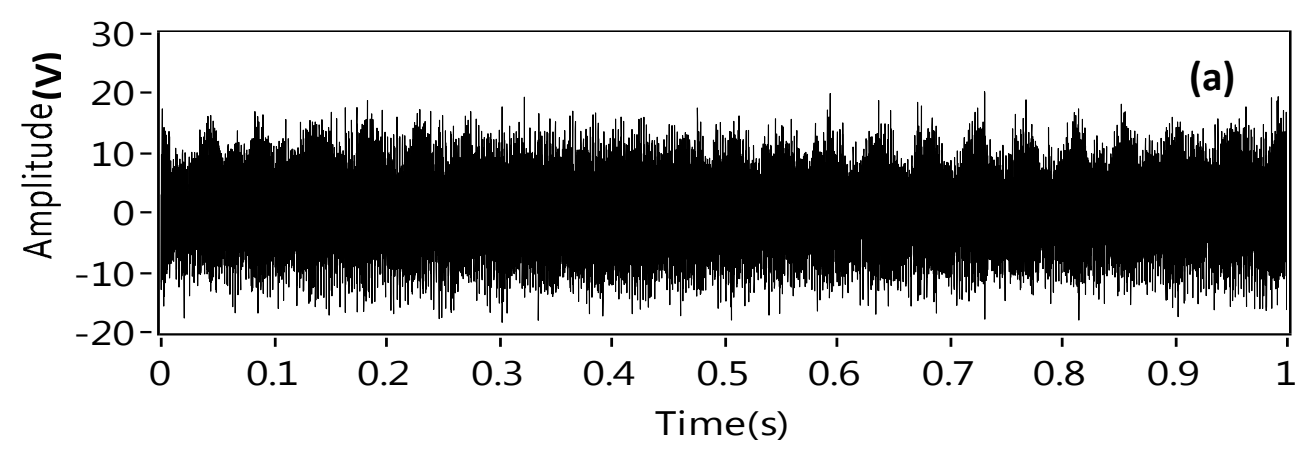




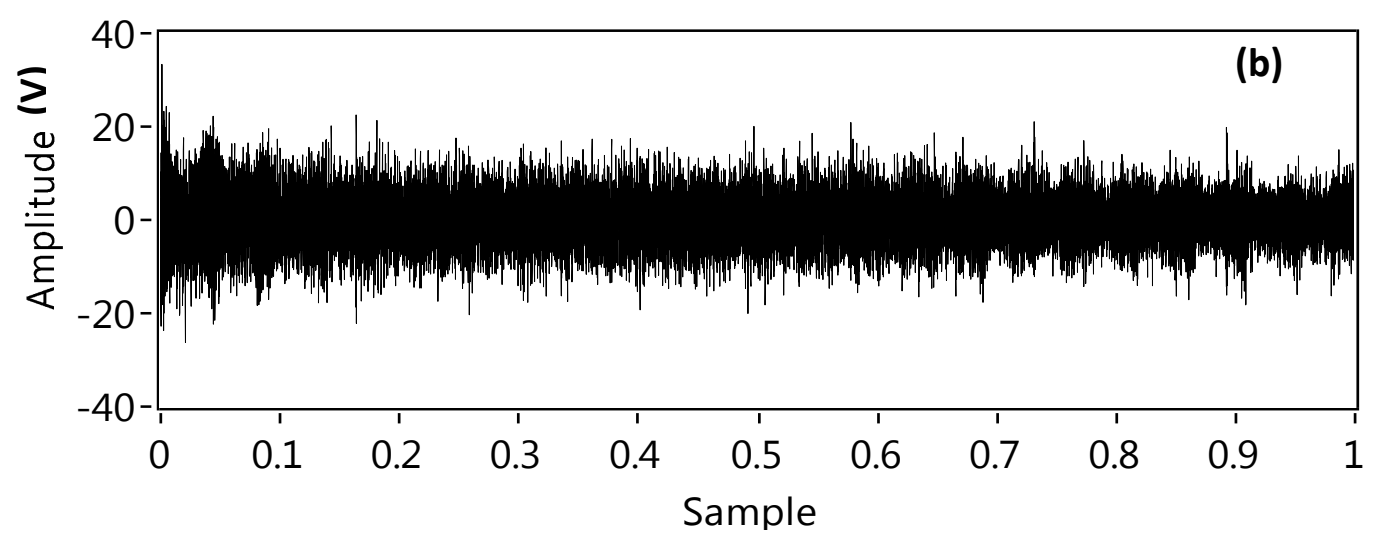

Figure 14 Time waveform of vibration signatures (a) before and (b) after separation for small defect

The measured vibration data was processed to estimate the power spectrum of the vibration signal for both damaged and fault-free conditions, see figure 15. This analysis was performed to assess the ability of FFT spectrum to determine the presence of a fault. The results showed no f fault frequencies, however, spectrum of major defect shows increased activity at both the lower frequencies $(0-2.5 \mathrm{KHz})$ and higher frequencies $(22.5-25 \mathrm{KHz})$. Therefore, the data was further processed using signal separation and Spectral Kurtosis to identify the fault signature as described earlier. 

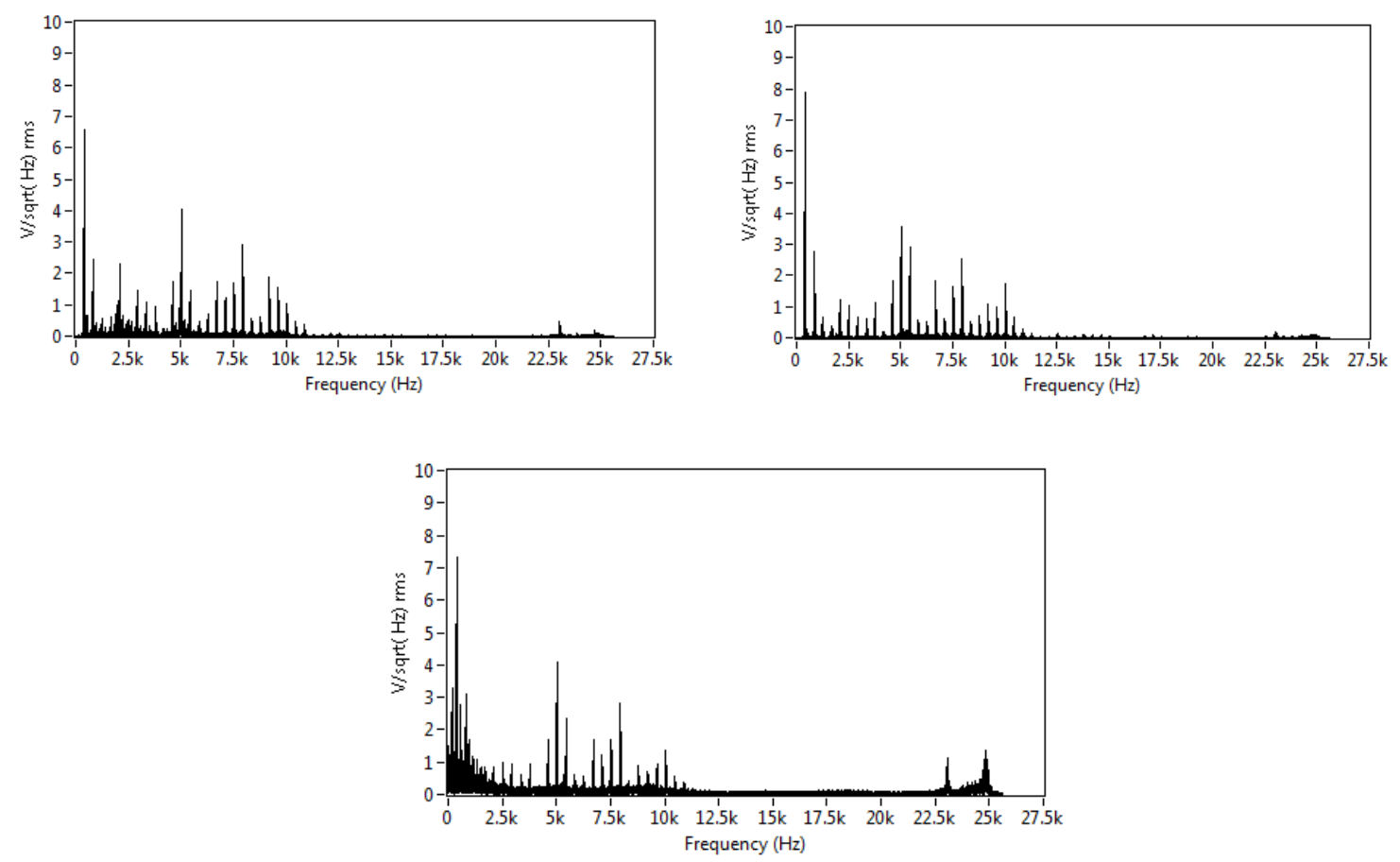

Figure 15 Power spectrum of original vibration signal for (a) fault-free (b) small defect (c) large defect conditions

The Spectral Kurtosis analysis was undertaken on data sets collected from the gearbox for the different fault cases and this yielded the frequency bands and center frequencies which were then used to undertake the envelope analysis. An example kurtogram used to estimate filter characteristics for different defect conditions is shown in figure 16. The filter frequency bands for each data set case are summarised in table 3. Spectral plots of enveloped vibration signals following filtration, whose characteristics were determined with the aid of the kurtogram, are shown in figures 9 to 11 . 
fb-kurt.1-K $=0.1 @$ level $5, B w=800 \mathrm{~Hz}, \mathrm{f}=18000 \mathrm{~Hz}$

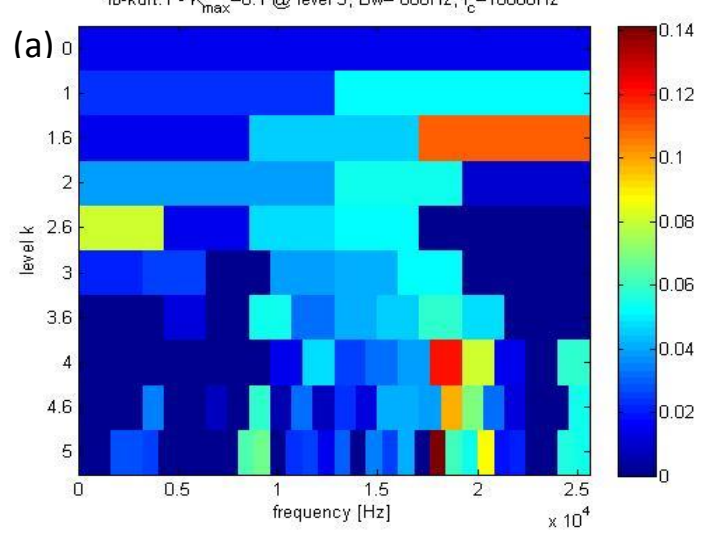

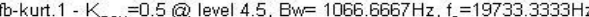

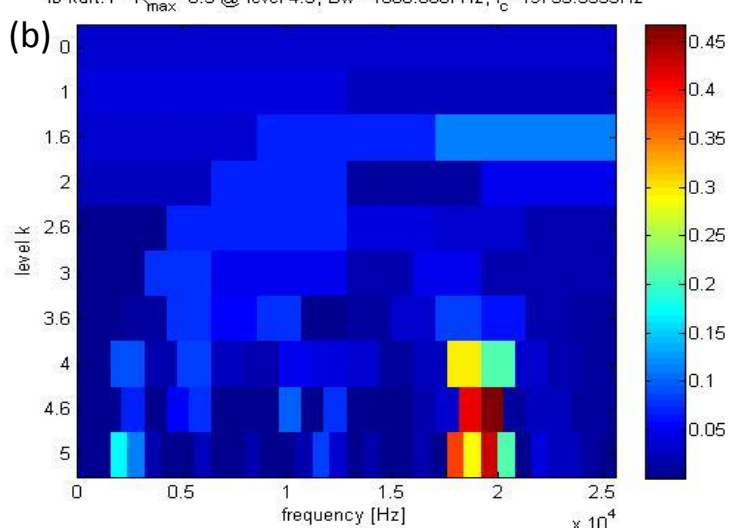

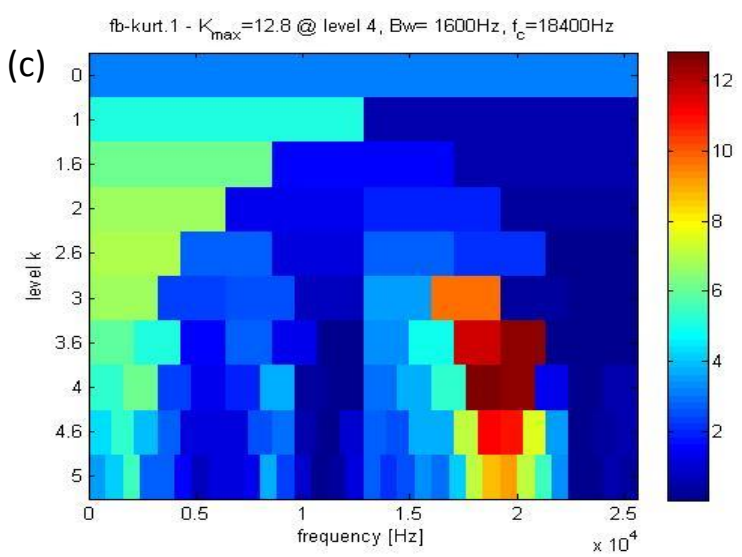

Figure 16 SK of $X$ direction of non-deterministic signal for (a) Fault-free (b) small defect (c) large defect

Table 3 Filter characteristics estimated based on SK for all three vibration axes

\begin{tabular}{|l|c|c|c|}
\hline Case & $\begin{array}{l}\text { Center frequency } \\
\mathbf{F}_{\mathbf{c}}\end{array}$ & $\begin{array}{l}\text { Band Width } \\
\text { Bw }\end{array}$ & Kurtosis \\
\hline Fault-free condition X direction & 18000 & 800 & 0.1 \\
\hline Fault-free condition Y direction & 18200 & 750 & 0.11 \\
\hline Fault-free condition Z direction & 17920 & 789 & 0.14 \\
\hline Small defect X direction & 19733 & 1066 & 0.5 \\
\hline Small defect Y direction & 18920 & 1080 & 0.55 \\
\hline Small defect Z direction & 20083 & 917 & 0.45 \\
\hline Large defect X direction & 18400 & 1600 & 12.8 \\
\hline Large defect Y direction & 18400 & 1600 & 12.8 \\
\hline Large defect Z direction & 18400 & 1600 & 12.8 \\
\hline
\end{tabular}


Observation from the spectra of the enveloped signal in the X-direction, see figure 17 , showed the presence in the spectrum of the large defect. Typical outer race defect frequency $(192 \mathrm{~Hz})$, it's $2^{\text {nd }}$ harmonic $(384 \mathrm{~Hz})$, the $3^{\text {rd }}$ harmonic $(576 \mathrm{~Hz})$ and $4^{\text {th }}$ harmonics $(768 \mathrm{~Hz})$ were detected for the large defect condition. However, the small fault condition was not identified in its corresponding frequency spectrum. It is apparent that the signal separation still had not completely removed the gear mesh and shaft frequencies, which were detected by envelope analysis.
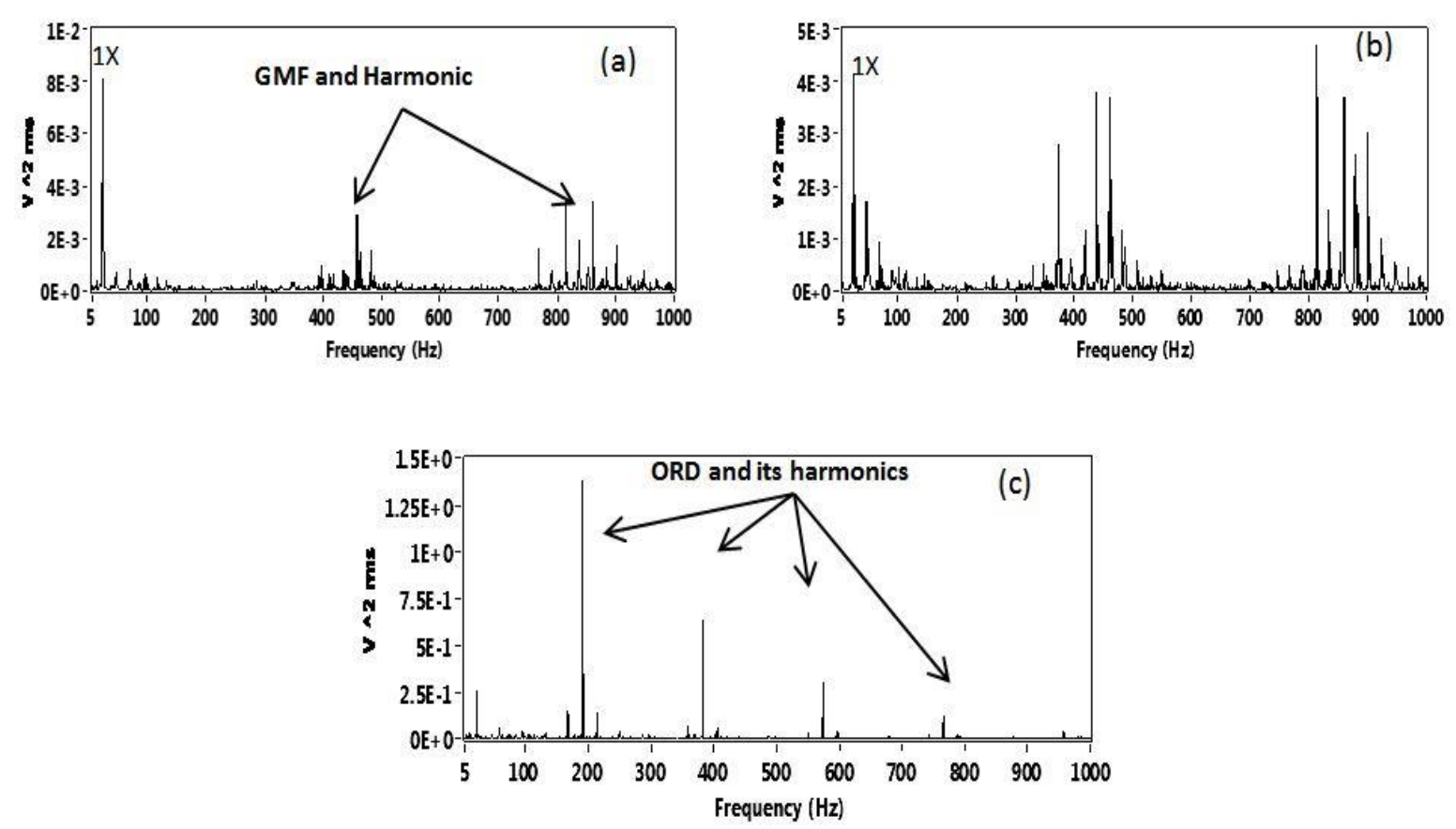

Figure 17 Enveloped Spectra of $X$ direction non-deterministic signal for (a) Fault-free (b) small size defect (c) large size defect conditions

Observation of the results in the $Y$ and $Z$ measurement directions, see figures 18 and 19 , show outer race defect frequencies $(192 \mathrm{~Hz})$ and its harmonics for the large defect whilst no fault frequency was identified in envelope spectra for the small bearing defect, reinforcing the observations of measurement taken in the $\mathrm{X}$ direction. It is worth mentioning the gear mesh frequency $(425 \mathrm{~Hz})$ and the idler shaft frequency $(23.6 \mathrm{~Hz})$ were dominant in the frequency spectrum except for the large bearing defect condition, where the bearing outer race fault frequency was more prominent. 

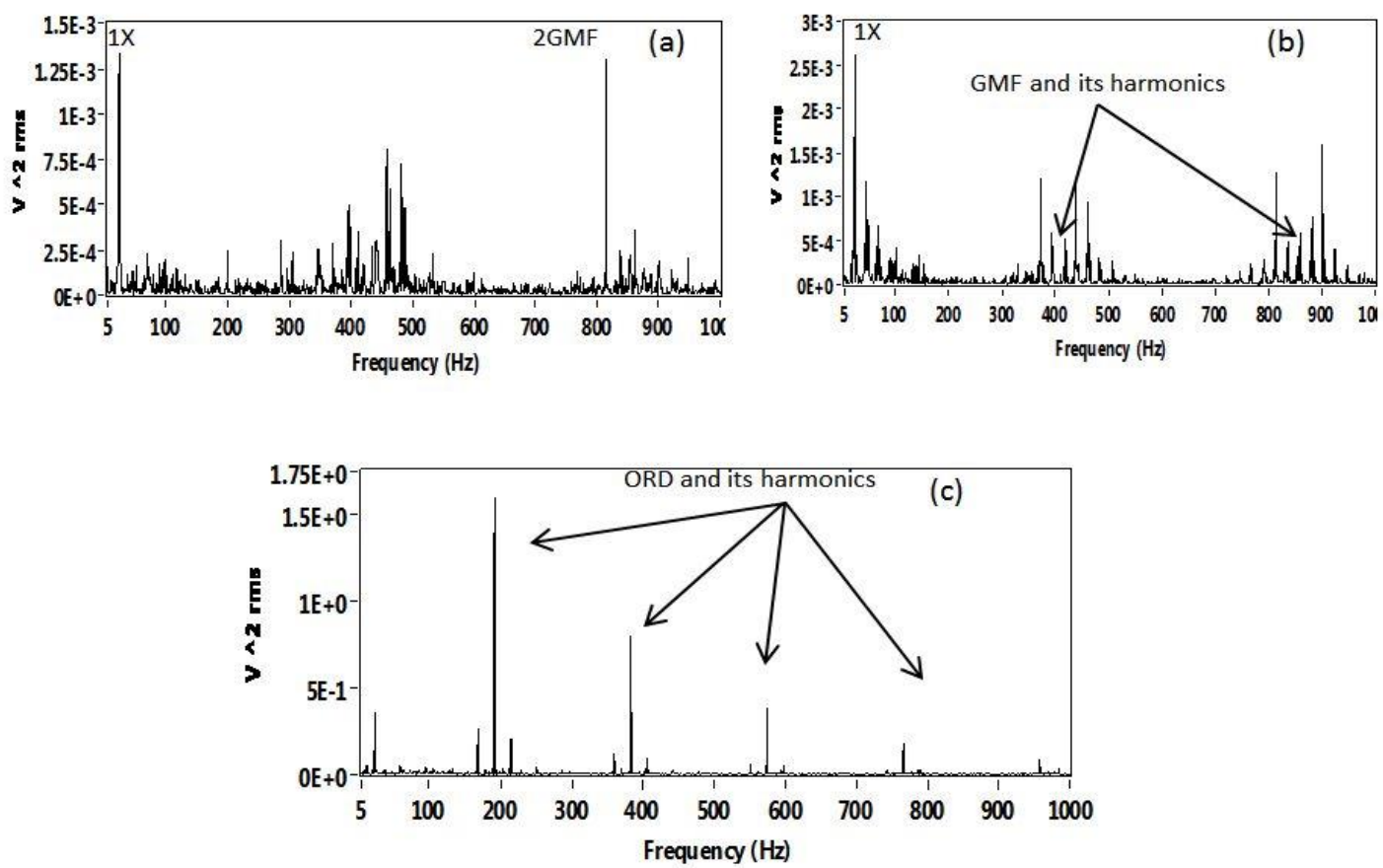

Figure 18 Enveloped Spectra of $Y$ direction non-deterministic signal for (a) Fault-free (b) small size defect (c) large size defect conditions
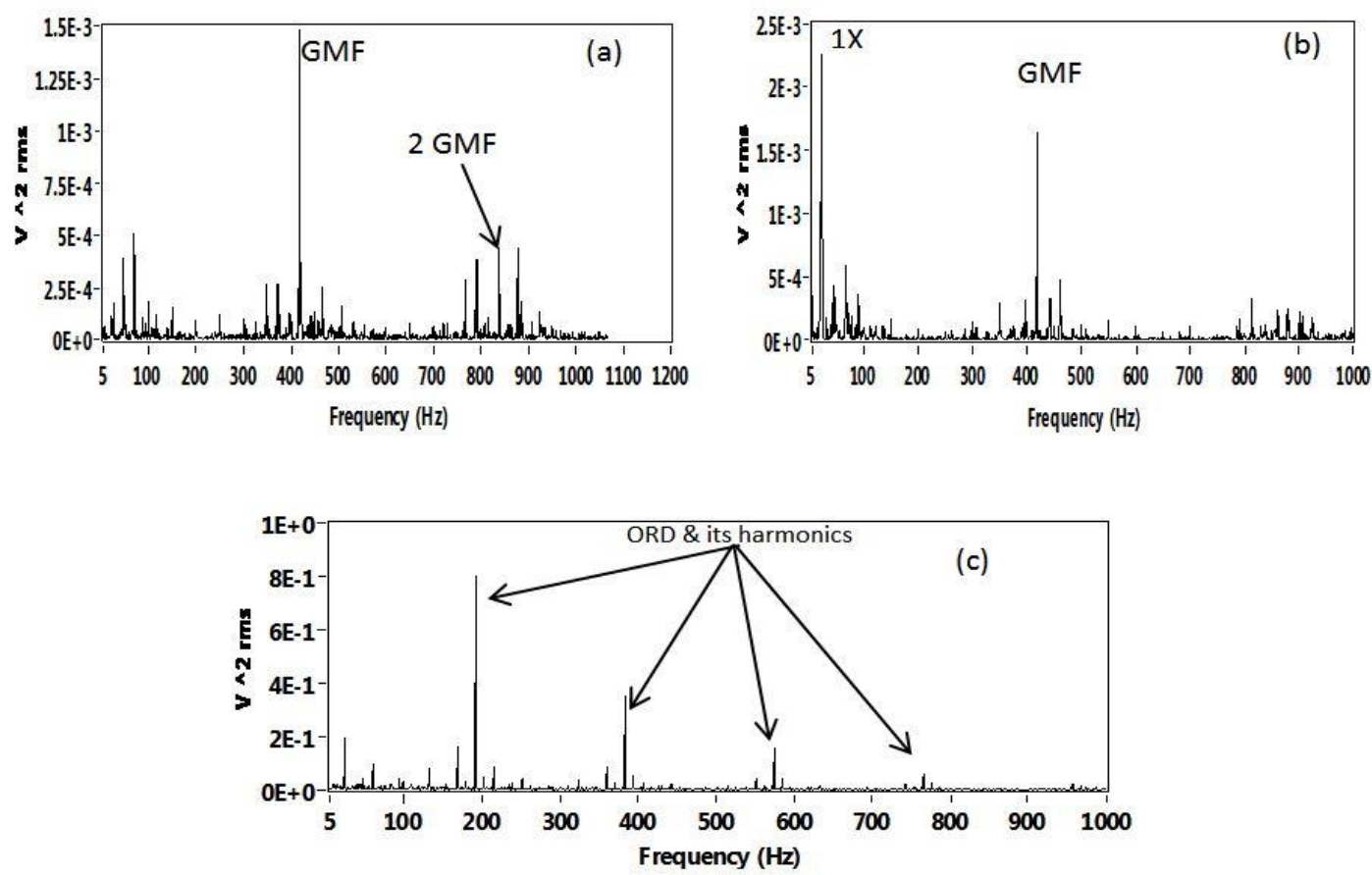

Figure 19 Enveloped Spectra of Z direction non-deterministic signal for (a) Fault-free (b) small size defect (c) large size defect conditions 


\subsection{Acoustic Emission observations}

Figure 20 (a) shows the AE signature prior to, and after signal separation of the deterministic components. Figure 15 (b) clearly exhibited periodic shocks events that were masked by background noise in the original time trace, figure 15 (a)
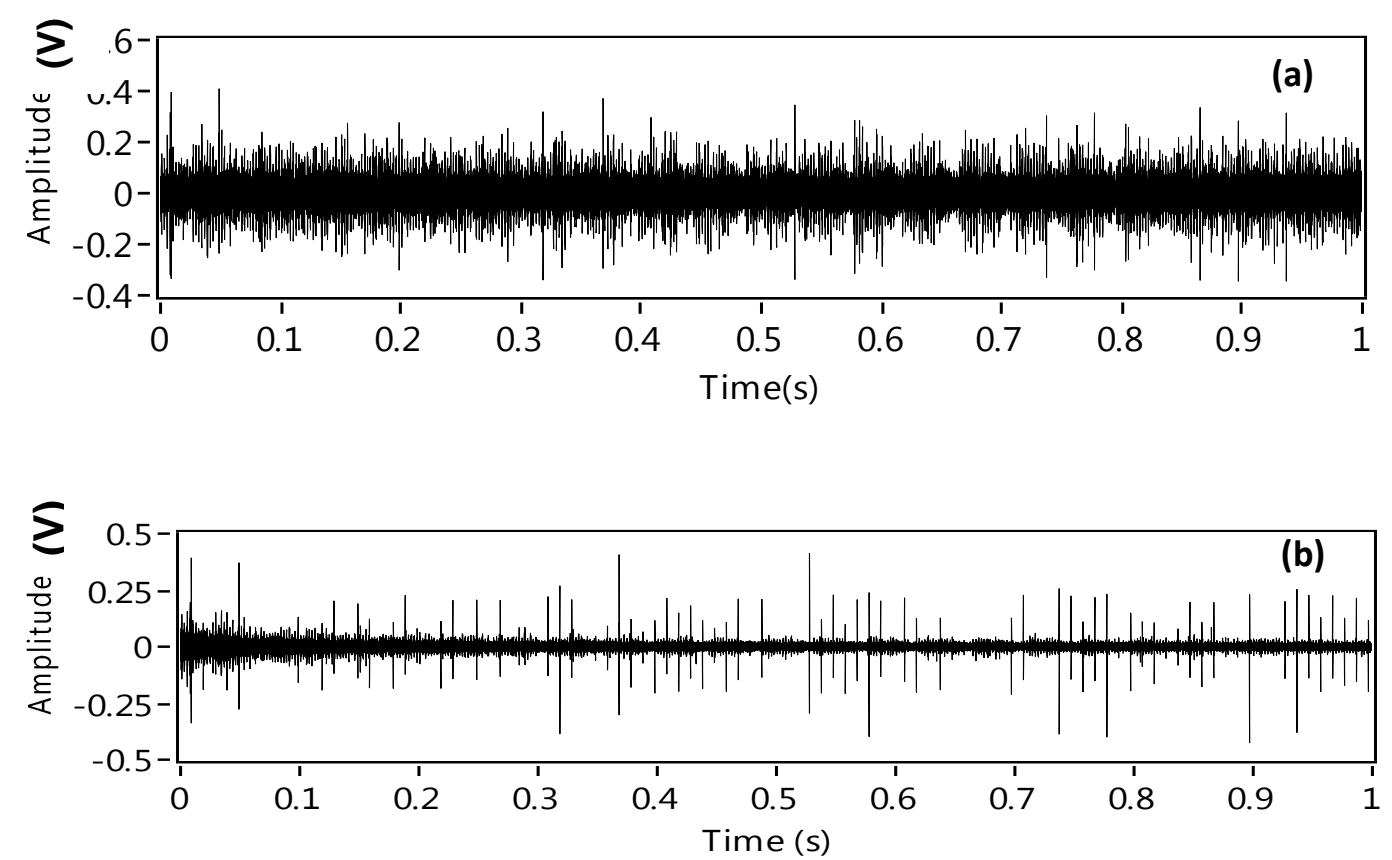

Figure 20 Time waveform of AE signal (a) before and (b) after separation for small defect

The Spectral Kurtosis was employed to extract the filter characteristics which were utilised for envelope analysis on the non-deterministic component of the $A E$ signature. Associated typical kurtograms of SK analysis are shown in figure 21. The overall maximum kurtosis for defective bearing conditions was significantly higher compared to fault-free condition which was 3 , the maximum kurtosis increased by $600 \%$ for the small outer race defect (18.5) and $3000 \%$ for severe defect condition (91.7) in comparison to the fault-free condition (3). 

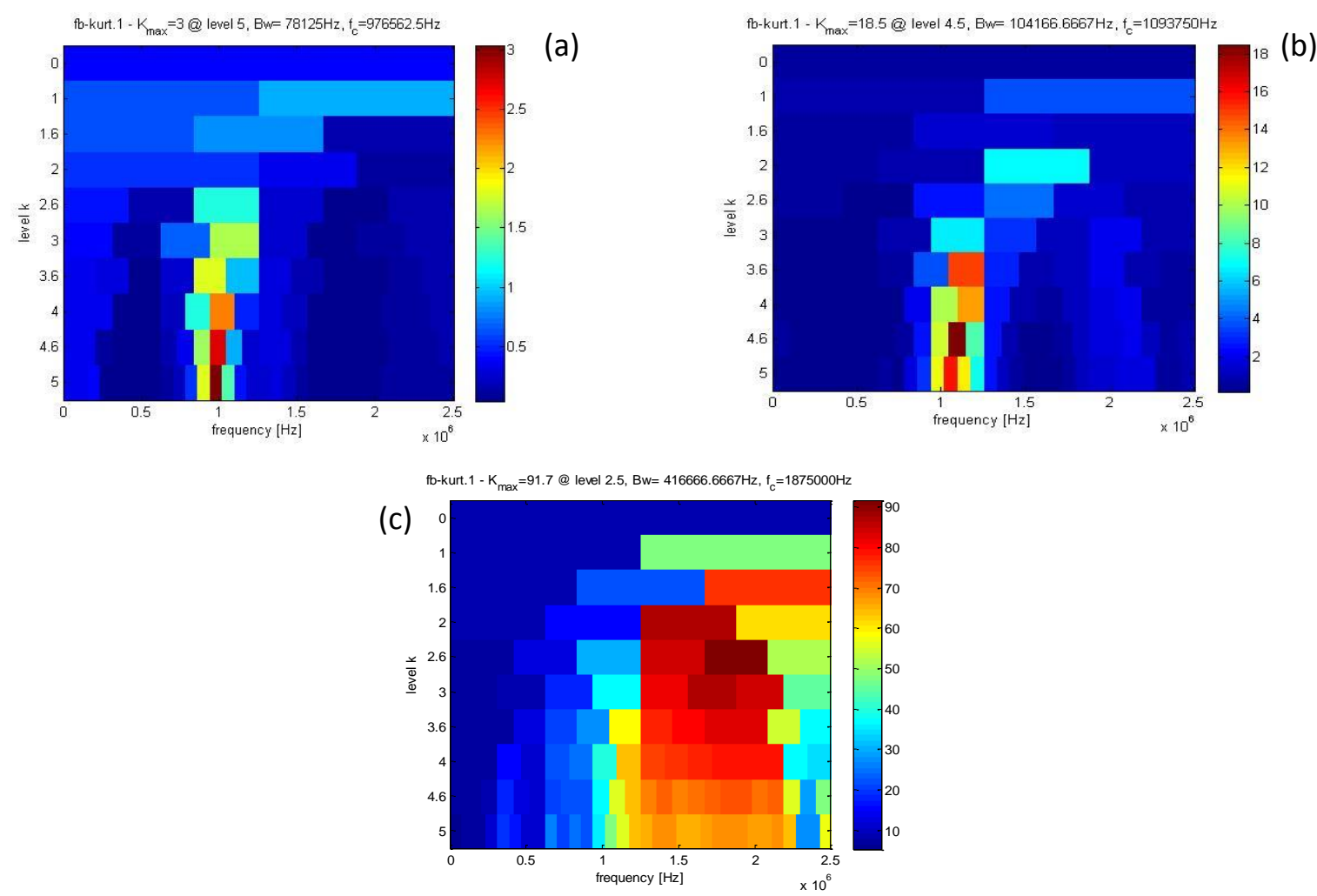

Figure 21 SK kurtograms (a) Fault-free (b) small (c) large bearing defects

The envelope analysis was undertaken using the central frequency $F_{c}$ and bandwidth (Bw) estimated by SK analysis, see table 4. Filter characteristics provided by the Spectral Kurtosis meant that the filtered $A E$ response had a frequency band above $40 \mathrm{KHz}$. To aid identification o the bearing defect frequencies the autors present frequency spectra from $0-500 \mathrm{~Hz}$. Observations of Figure 22 (b) showed the presence of the bearing outer race defect frequency $(192 \mathrm{~Hz})$ for the small defect condition. In addition, the outer race defect frequency, and its harmonics, were observed for large defect condition (192 Hz and $384 \mathrm{~Hz}$ ).

Table 4 Filter characteristics estimated based on SK for AE signals

\begin{tabular}{|l|l|l|l|}
\hline Case & \multicolumn{1}{|c|}{ Center frequency $F_{c}$} & Band Width (Bw) & Kurtosis \\
\hline Fault-free condition & 976562.5 & 87125 & 3.0 \\
\hline Small defect & 1093750 & 104166 & 18.5 \\
\hline Large defect & 1875000 & 416666 & 91.7 \\
\hline
\end{tabular}



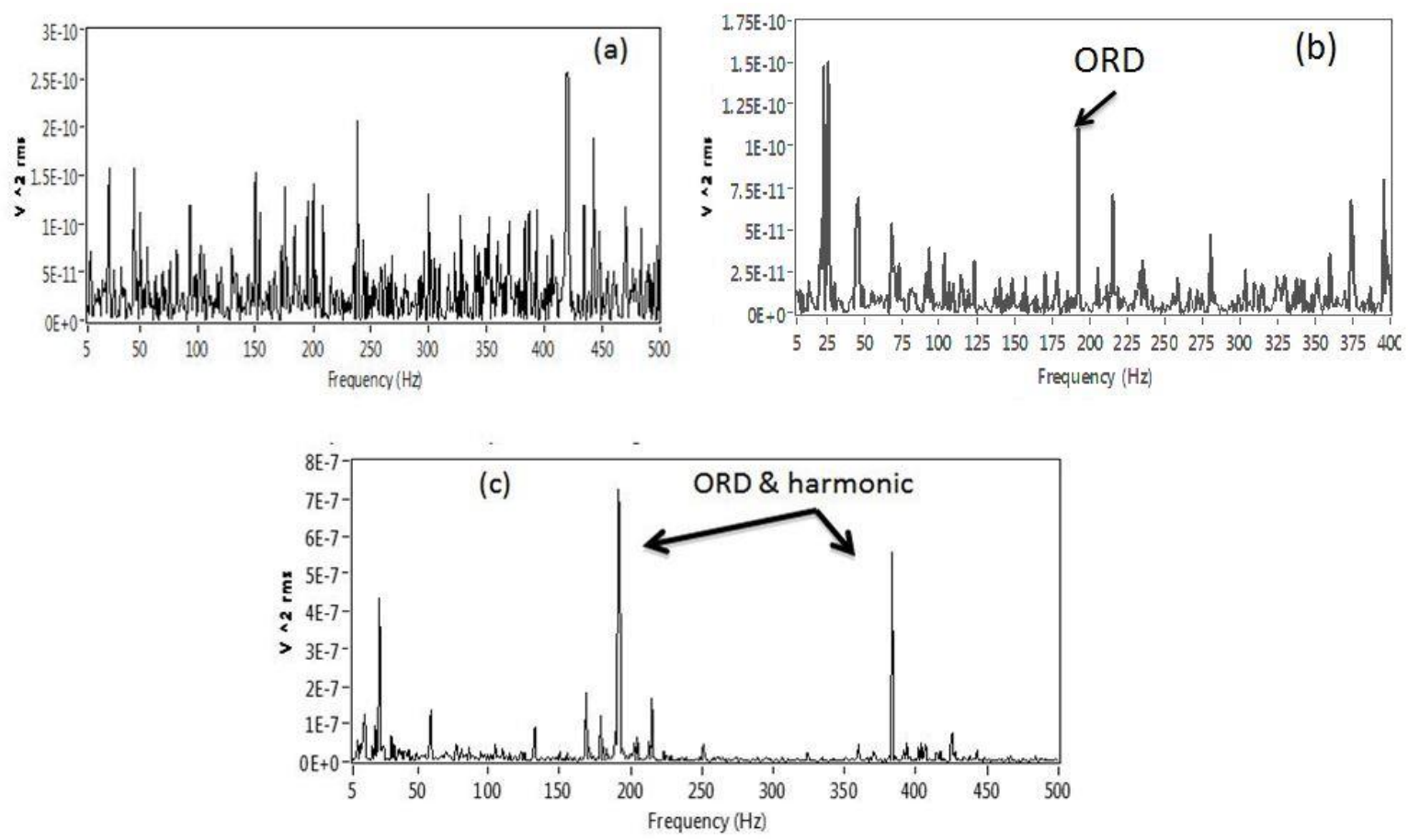

Figure 22 Enveloped spectra of AE signal (a) Fault-free (b) small (c) large bearing defects

\section{Full test preliminary results}

A typical AE waveform associated with $100 \%$ maximum continuous power is presented in figure 18. Noted was the intermittent breakup of the AE signal, as highlighted in figure 18. The frequency of the signal loss corresponded to the second epicyclic stage gear mesh frequency. Irrespective of this signal breakage further processing was undertaken on the acquired waveform.

Figure 19 shows the enveloped random signal for the case of minor damage at $110 \%$ maximum take- off power. The outer race defect frequencies and harmonics are clearly visible whereas the undamaged case contained no such harmonics. It can be concluded from this that the sensor is providing useful information across the wireless link at a wide range of frequencies, opening the potential for improved detection. 


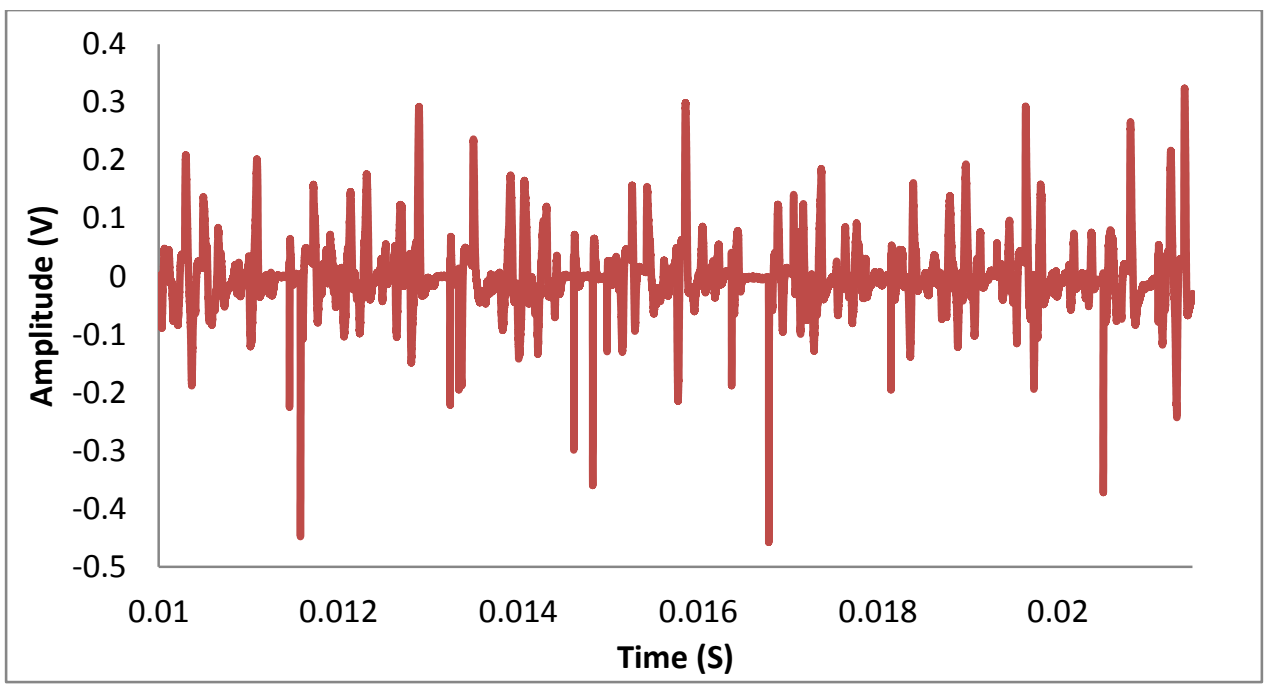

Figure 23 Typical signal from PWAS over wireless transmission

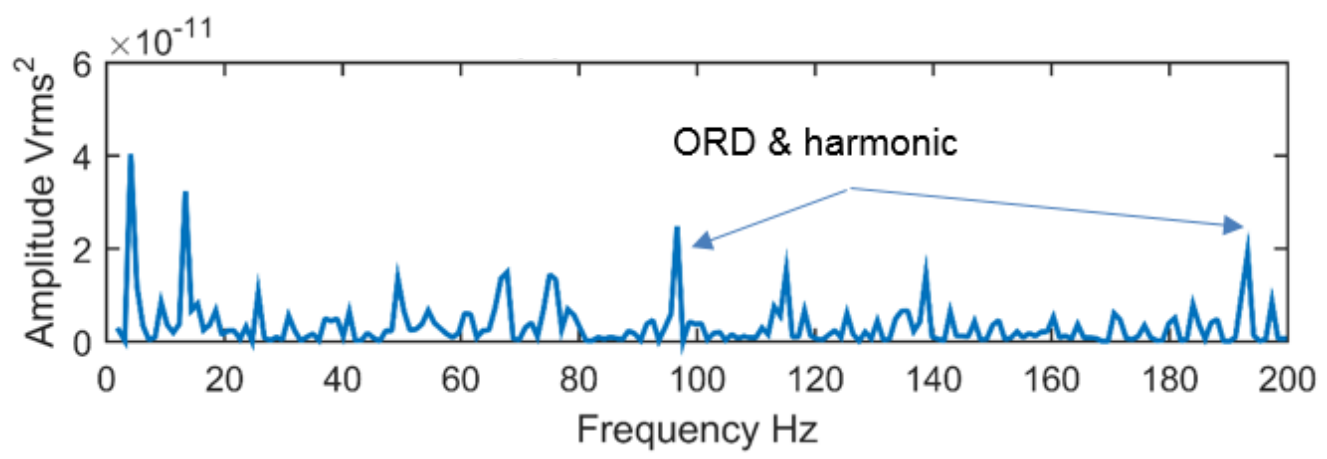

Figure 24 Frequency spectrum of PWAS signal

\section{Discussion and conclusion}

This research programme has resulted in a successful proof of concept of broadband wireless transmission, including power scavenging, coupled with smallscale broadband sensors, working successfully in an operational environment. This result presents a new range of potential fault diagnosis opportunities for a future 0 HUMS systems.

The signal processing techniques used in this paper are typically used for applications where strong background noise masks the defect signature of interest within the measured vibration signature. The AE signal is more susceptible to background noise and in this case, the arduous transmission path from the outer race through the rollers to the inner race and then the shaft makes the ability to 
identify outer race defects even more challenging. Therefore, the use of signal separation to offer further insight into diagnostic information is deemed necessary for application of $A E$ in the diagnosis of planetary gearboxes. However, the use of internal $A E$ internal sensor showed the effect of the arduous transmission has been significantly reduced.A comparison of the vibration and $A E$ analysis showed both measurements were able to identify the presence of the large bearing defect based on observations in the enveloped spectra. For the small defect condition, however, the enveloped spectrum was dominated by the gear mesh frequencies and their harmonics, and as such the bearing defect frequencies were not evident. However, $\mathrm{AE}$ analysis was able to identify both the small and large defect conditions. Detection of the small bearing defect gives the $\mathrm{AE}$ an indisputable diagnosis advantage over the vibration analysis. Though this should be qualified by noting the position of $A E$ sensor was closer to the defect.The ability of applied signal processing techniques to identify the presence of bearing fault is based on removing the masked signal and the identification of particular frequency regions with high impact energy; these impacts are due to presence of bearing defect which affect bearing sliding motion. Results of vibration analysis show sensitivity to the direction of vibration measurement.

In summary, an investigation employing vibration and $A E$ to identify the presence of a bearing defect in a planetary type arrangement has been undertaken. A series of signal processing techniques were applied to extract the bearing fault signature, which included adaptive filter, Spectral Kurtosis, and envelope analysis. The combination of these techniques demonstrated the ability to identify the presence of the various defect sizes of bearing in comparison to a typical frequency spectrum. From the results presented it was clearly evident that the $A E$ offered much earlier indication of damage than vibration analysis. In addition, the signal processing techniques demonstrated the capability to successfully apply $A E$ to gearbox fault diagnosis.

\section{Acknowledgements}

This work was sponsered by European Aviation safety agency (EASA 2012.OP.13. VHM). 


\section{References}

[1] Cotrell, J. R. (2002), "A preliminary evaluation of a multiple-generator drivetrain configuration for wind turbines", ASME 2002 Wind Energy Symposium, American Society of Mechanical Engineers, pp. 345.

[2] Lynwander, P. (1983), Gear drive systems: design and application, CRC Press.

[3] Kahraman, A. (1994), "Planetary gear train dynamics", Journal of Mechanical Design, vol. 116, no. 3, pp. 713-720.

[4] Huang, C., Tsai, M., Dorrell, D. G. and Lin, B. (2008), "Development of a magnetic planetary gearbox", Magnetics, IEEE Transactions on, vol. 44, no. 3, pp. 403-412.

[5] P., R. (2012), Dudley's Handbook of Practical Gear Design and Manufacture, second ed, CRC press, USA.

[6] Bin Lu, Yaoyu Li, Xin Wu and Zhongzhou Yang (2009), "A review of recent advances in wind turbine condition monitoring and fault diagnosis", Power Electronics and Machines in Wind Applications, 2009. PEMWA 2009. IEEE, pp. 1.

[7] McFadden, P. D. (1987), "A revised model for the extraction of periodic waveforms by time domain averaging", Mechanical Systems and Signal Processing, vol. 1, no. 1, pp. 83-95.

[8] Randall, R. B. (2004), "Detection and diagnosis of incipient bearing failure in helicopter gearboxes", Engineering Failure Analysis, vol. 11, no. 2, pp. 177-190.

[9] Wang, W. (2001), "Early detection of gear tooth cracking using the resonance demodulation technique", Mechanical Systems and Signal Processing, vol. 15, no. 5, pp. 887-903.

[10] Musial, W., Butterfield, S. and McNiff, B. (2007), "Improving wind turbine gearbox reliability", Proceedings of the European wind energy conference, .

[11] Department for Transport (2011), Report on the accident to aerospatiale (Eurrocopter) AS332 L2 Super Puma,registration G-REDL 11 nm NE of Peterhead, Scotland, on 1 April 2009 , 2/2011, Air Accident Investigation Branch, Aldershot, UK. 
[12] Samuel, P. D. and Pines, D. J. (2005), "A review of vibration-based techniques for helicopter transmission diagnostics", Journal of Sound and Vibration, vol. 282, no. 1-2, pp. $475-508$.

[13] McFadden, P. D. and Toozhy, M. M. (2000), "Application of Synchronous Averaging to Vibration Monitoring of rolling elements bearings", Mechanical Systems and Signal Processing, vol. 14, no. 6, pp. 891-906.

[14] Sawalhi, N., Randall, R. B. and Forrester, D. (2014), "Separation and enhancement of gear and bearing signals for the diagnosis of wind turbine transmission systems", Wind Energy, vol. 17, no. 5, pp. 729-743.

[15] McFadden, P. D. and Smith, J. D. (1984), "Vibration monitoring of rolling element bearings by the high-frequency resonance technique - a review", Tribology International, vol. 17, no. 1, pp. 3-10.

[16] Yang, W., Tavner, P. J. and Wilkinson, M. R. (2009), "Condition monitoring and fault diagnosis of a wind turbine synchronous generator drive train", Renewable Power Generation, IET, vol. 3, no. 1, pp. 1-11.

[17] Wenxian Yang, Tavner, P. J., Crabtree, C. J. and Wilkinson, M. (2010), "CostEffective Condition Monitoring for Wind Turbines", Industrial Electronics, IEEE Transactions on, vol. 57, no. 1, pp. 263-271.

[18] Randall, R. B., Sawalhi, N. and Coats, M. (2011), "A comparison of methods for separation of deterministic and random signals", The International Journal of Condition Monitoring, vol. 1, no. 1, pp. 11.

[19] Randall, R. B. and Antoni, J. (2011), "Rolling element bearing diagnostics-A tutorial", Mechanical Systems and Signal Processing, vol. 25, no. 2, pp. 485-520.

[20] Antoni, J. and Randall, R. B. (2001), "optimisation of SANC for Separating gear and bearing signals", Condition monitoring and diagnostics engineering management, , no. 1, pp. 89-99.

[21] Ho, D. and Randall, R. B. (2000), "Optimisation of bearing diagnostic techniques using simulated and actual bearing fault signal", Mechanical Systems and Signal Processing, vol. 14, no. 5, pp. 763-788. 
[22] Antoni, J. (2005), "Blind separation of vibration components: Principles and demonstrations", Mechanical Systems and Signal Processing, vol. 19, no. 6, pp. 11661180.

[23] Li, Z., Yan, X., Tian, Z., Yuan, C., Peng, Z. and Li, L. (2013), "Blind vibration component separation and nonlinear feature extraction applied to the nonstationary vibration signals for the gearbox multi-fault diagnosis", Measurement, vol. 46, no. 1, pp. 259-271.

[24] Barszcz, T. (2009), "Decomposition of vibration signals into deterministic and nondeterministic components and its capabilities of fault detection and identification", International Journal of Applied Mathematics and Computer Science, vol. 19, no. 2, pp. 327-335.

[25] Randall, R. B. (2011), Vibration-based Condition Monitoring, first ed, John Wiley and sons Ltd, UK.

[26] Wang, W. (2008), "Autoregressive model-based diagnostics for gears and bearings", Insight-Non-Destructive Testing and Condition Monitoring, vol. 50, no. 8, pp. 414-418.

[27] Makhoul, J. (1975), "Linear prediction: A tutorial review", Proceedings of the IEEE, vol. 63 , no. 4 , pp. 561-580.

[28] Satorius, E. H., Zeidler, J. R. and Alexander, S. T. (1979), "Noise cancellation via linear prediction filtering", Acoustics, Speech, and Signal Processing, IEEE International Conference on ICASSP' '79. Vol. 4, pp. 937.

[29] Thakor, N. V. and Zhu, Y. (1991), "Applications of adaptive filtering to ECG analysis: noise cancellation and arrhythmia detection", Biomedical Engineering, IEEE Transactions on, vol. 38, no. 8, pp. 785-794.

[30] Chaturved, G. K. and Thomas, D. W. (1981), "Adaptive noise cancelling and condition monitoring", Journal of Sound and Vibration, vol. 76, no. 3, pp. 391-405.

[31] Antoni, J. and Randall, R. B. (2004), "Unsupervised noise cancellation for vibration signals: part l-evaluation of adaptive algorithms", Mechanical Systems and Signal Processing, vol. 18, no. 1, pp. 89-101. 
[32] Widrow, B., Glover, J. R., Jr., McCool, J. M., Kaunitz, J., Williams, C. S., Hearn, R. H., Zeidler, J. R., Eugene Dong, J. and Goodlin, R. C. (1975), "Adaptive noise cancelling: Principles and applications", Proceedings of the IEEE, vol. 63, no. 12, pp. 1692-1716.

[33] Simon, H. (1991), Adaptive Filter theory, Second ed, Prentice-Hall international, Inc, USA.

[34] Ruiz-Cárcel, C., Hernani-Ros, E., Cao, Y. and Mba, D. (2014), "Use of Spectral Kurtosis for Improving Signal to Noise Ratio of Acoustic Emission Signal from Defective Bearings", Journal of Failure Analysis and Prevention, vol. 14, no. 3, pp. 363-371.

[35] Antoni, J. and Randall, R. (2006), "The spectral kurtosis: application to the vibratory surveillance and diagnostics of rotating machines", Mechanical Systems and Signal Processing, vol. 20, no. 2, pp. 308-331.

[36] Antoni, J. (2007), "Fast computation of the kurtogram for the detection of transient faults", Mechanical Systems and Signal Processing, vol. 21, no. 1, pp. 108-124.

[37] Dwyer, R. (1983), "Detection of non-Gaussian signals by frequency domain kurtosis estimation", Acoustics, Speech, and Signal Processing, IEEE International Conference on ICASSP'83. Vol. 8, IEEE, pp. 607.

[38] Holroyd, T. (2000), "Acoustic Emission as a basis for the condition monitoring of industrial machinery", Proceedings of the 18 th Machinery vibration seminar, Canadian Machinery vibration association, pp. 27.

[39] Eftekharnejad, B., Carrasco, M., Charnley, B. and Mba, D. (2011), "The application of spectral kurtosis on acoustic emission and vibrations from a defective bearing", Mechanical Systems and Signal Processing, vol. 25, no. 1, pp. 266-284.

[40] Kilundu, B., Chiementin, X., Duez, J. and Mba, D. (2011), "Cyclostationarity of Acoustic Emissions (AE) for monitoring bearing defects", Mechanical systems and signal Processing, vol. 25, no. 6, pp. 2061-2072.

[41] Mba, D. and Rao, R. B. (2006), "Development of Acoustic Emission Technology for Condition Monitoring and Diagnosis of Rotating Machines; Bearings, Pumps, Gearboxes, Engines and Rotating Structures.", . 
[42] Mba, D. (1998), Condition Monitoring of Slow Speed Rotating Machinary using Stress Waves (PhD thesis), Cranfield University, UK.

[43] Tan, C. K., Irving, P. and Mba, D. (2007), "A comparative experimental study on the diagnostic and prognostic capabilities of acoustics emission, vibration and spectrometric oil analysis for spur gears", Mechanical Systems and Signal Processing, vol. 21, no. 1, pp. 208-233.

[44] Al-Ghamd, A. M. and Mba, D. (2006), "A comparative experimental study on the use of acoustic emission and vibration analysis for bearing defect identification and estimation of defect size", Mechanical Systems and Signal Processing, vol. 20, no. 7 , pp. 1537-1571.

[45] Mba, D. (2005), "Prognostic opportunities offered by acoustic emission for monitoring bearings and gearboxes", Twelfth international congress on sound and vibration, .

[46] Couturier, J. and Mba, D. (2008), "Operational bearing parameters and acoustic emission generation", Journal of Vibration and Acoustics, vol. 130, no. 2, pp. 024502.

[47] Sikorska, J. and Mba, D. (2008), "Challenges and obstacles in the application of acoustic emission to process machinery", Proceedings of the Institution of Mechanical Engineers, Part E: Journal of Process Mechanical Engineering, vol. 222, no. 1, pp. 1-19.

[48] Eftekharnejad, B. and Mba, D. (2009), "Seeded fault detection on helical gears with acoustic emission", Applied Acoustics, vol. 70, no. 4, pp. 547-555.

[49] Elforjani, M. and Mba, D. (2008), "Monitoring the onset and propagation of natural degradation process in a slow speed rolling element bearing with acoustic emission", Journal of Vibration and Acoustics, vol. 130, no. 4, pp. 041013.

[50] Al-Balushi, K. R., Addali, A., Charnley, B. and Mba, D. (2010), "Energy Index technique for detection of Acoustic Emissions associated with incipient bearing failures", Applied Acoustics, vol. 71, no. 9, pp. 812-821.

[51] Qu, Y., Van Hecke, B., He, D., Yoon, J., Bechhoefer, E. and Zhu, J. (2013), "Gearbox Fault Diagnostics using AE Sensors with Low Sampling Rate", J. Acoustic Emission, vol. 31, pp. 67. 
[52] Elforjani, M., Mba, D., Muhammad, A. and Sire, A. (2012), "Condition monitoring of worm gears", Applied Acoustics, vol. 73, no. 8, pp. 859-863.

[53] Howard, I. (1994), A review of rolling element bearing vibration " Detection, Diagnosis and Prognosis", DSTO-RR-0013, Department of defense.

[54] Khemili, I. and Chouchane, M. (2005), "Detection of rolling element bearing defects by adaptive filtering", European Journal of Mechanics - A/Solids, vol. 24, no. 2, pp. 293303.

[55] Bonnardot, F., El Badaoui, M., Randall, R. B., Danière, J. and Guillet, F. (2005), "Use of the acceleration signal of a gearbox in order to perform angular resampling (with limited speed fluctuation)", Mechanical Systems and Signal Processing, vol. 19, no. 4, pp. 766-785.

[56] Sait, A. and Sharaf-Eldeen, Y. (2011), "A Review of Gearbox Condition Monitoring Based on vibration Analysis Techniques Diagnostics and Prognostics", in Proulx, T. (ed.) Rotating Machinery, Structural Health Monitoring, Shock and Vibration, Volume 5, Springer New York, , pp. 307-324.

[57] Martin, H.,R. (1989), "Statistical Moment Analysis as a Means of Surface Damage Detection", Proceeding of the 7th International Model Analysis Conference, Society of Experimental Mechanics, , pp. 1016-1021.

[58] Mehala, N. and Dahiya, R. (2008), "A comparative study of FFT, STFT and wavelet techniques for induction machine fault diagnostic analysis", Proceedings of the 7th WSEAS international conference on Computational intelligence, man-machine systems and cybernetics, Cairo, Egypt, World Scientific and Engineering Academy and Society, WSEAS; Stevens Point, Wisconsin, USA, pp. 203.

[59] Wang, W. J. and McFadden, P. D. (1996), "APPLICATION OF WAVELETS TO GEARBOX VIBRATION SIGNALS FOR FAULT DETECTION", Journal of Sound and Vibration, vol. 192, no. 5, pp. 927-939.

[60] Wang, W. J. and McFadden, P. D. (1993), "Early detection of gear failure by vibration analysis i. calculation of the time-frequency distribution", Mechanical Systems and Signal Processing, vol. 7, no. 3, pp. 193-203.

[61] Douglas, S. C. (1999), Introduction to Adaptive Filters, CRC Press. 
[62] Douglas, S. C. and Rupp, M. (1999), "Convergence Issues in the LMS Adaptive Filter", in Madisetti, V. K. (ed.) The Digital signal processing handbook, Second ed, CRC press, Atlanta, USA.

[63] Widrow, B., McCool, J. and Ball, M. (1975), "The complex LMS algorithm", Proceedings of the IEEE, vol. 63, no. 4, pp. 719-720.

[64] Alan, D. (1998), Handbook of the condition monitoring techaniques and methodology, First edition ed, Chapman and Hall, London UK.

[65] Elasha, F., Mba, D. and Ruiz-Carcel, C. (2016), "A comparative study of adaptive filters in detecting a naturally degraded bearing within a gearbox", Case Studies in Mechanical Systems and Signal Processing, vol. 3, pp. 1-8.

[66] Sawalhi, N., Randall, R. B. and Endo, H. (2007), "The enhancement of fault detection and diagnosis in rolling element bearings using minimum entropy deconvolution combined with spectral kurtosis", Mechanical Systems and Signal Processing, vol. 21, no. 6 , pp. 2616-2633.

[67] Pickwell, A. (2012), Design and Development of Micro-electromechanical Acoustic Emission Sensors (PhD Thesis thesis), Cranfield University, UK.

[68] Yu, L., Momeni, S., Godinez, V. and Giurgiutiu, V. (2011), "Adaptation of PWAS transducers to acoustic emission sensors", SPIE Smart Structures and Materials Nondestructive Evaluation and Health Monitoring, International Society for Optics and Photonics, pp. 798327. 